Dursun Saral

Muhsin Aydin

Ercan Kose

http://dx.doi.org/10.21278/brod69207

ISSN 0007-215X

eISSN 1845-5859

\title{
A SYSTEMATIC INVESTIGATION OF THE EFFECTS OF VARIOUS BULBOUS BOWS ON RESISTANCE OF FISHING BOATS
}

UDC 629.5.015.2: 629.5.024.32: 629.562

Original scientific paper

\section{Summary}

In this study, Delta $(\Delta)$, Nabla $(\nabla)$ and Elliptical $(\mathrm{O})$ shaped bulbs are implemented to ITU Fishing Boats Series hull forms of 148/3, 148/4, 148/8 and 148/9 in order to determine the most appropriate bulbous bow for fishing vessels. Initially, in defined Fn values, Computational Fluid Dynamics (CFD) analyses on four main forms are performed by using Realizable $\mathrm{k}-\varepsilon$ Model and Volume of Fluid (VOF) method. The total resistance values obtained by the CFD analyses and by the existing test results via Froude and Hughes methods are compared and examined. Thus, the method and reference values of CFD analyses are determined for the hull forms with bulbs which do not have test results. Subsequently, the CFD results of frictional resistance, pressure resistance and total resistance values for actual hulls and hulls with bulbs are compared. Following the examination of results in terms of $\mathrm{C}_{\mathrm{B}}$, $\mathrm{L} / \mathrm{B}$ and bulb types, it is determined that the elliptical bulb type is the most suitable bulb type for the fishing vessels.

Key words: $\quad$ Fishing Boat; Bulbous Bow; Computational Fluid Dynamics (CFD); Resistance;

\section{Introduction}

According to the culture of each country, certain forms of fishing boats have been developed according to needs over time. While improvements have been made in the main forms previously, the application of bulb to fishing boats is carried out because of that efficiency of bulb is observed today. The resistance analyses, which are made in model test basins, can be done on computers with the help of CFD softwares thanks to the development of technology.

The part of head of the ships, that is underwater, is inflated like a prominence or convexity, and it is called bulb [1]. The bulb forms are classified according to the form of the crosscut area of the head. As a general definition, there are three basic types of bulb geometry, namely, Delta $(\Delta)$, Circular-Elliptic $(\mathrm{O})$ and Nabla $(\nabla)$ sections [2]. The sections of the bulbs are shown in Figure 1. 


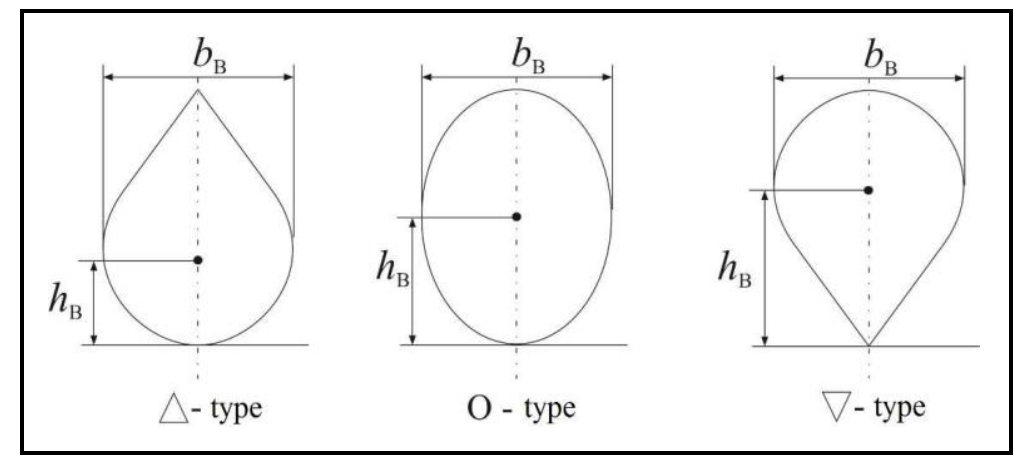

Fig. 1 The sections of the bulbs

Taylor [3] is the first researcher to experimentally investigate the effects of bulbs on ship form. Later, Bragg [4], Inui et al. [5], Ferguson [6], and Muntjewerf [7] experimentally conducted experiments on the $\Delta$ (delta) type, cylindrical and conical bulbs, which are known as Taylor bulbs, by systematically changing the bulb parameters. Weinblum [8], Wigley [9], Inui [10] and Yim [11] studied on the theory of linearized wave resistance theoretically. Inui [10] presented a method to determine the size of the bulb by matching amplitude functions of bulb in regular waves and stem. A connection for a speed has established between the entrance angle of ship head and the size of bulb by Yim [12]. A method consisting of three main subjects for designing spherical bulb was presented by Yim [13]. Again, Yim [14] discussed the sheltering effect on spherical bulbs. Baba [15] and, Shearer and Steele [16] pointed out that the bulb has benefits like; to reduce the wave breaks on stem, to improve the flow around keel line and bilge turn, as well as preventing flow separation on ship forms. Kracht [2] developed a statistical method from the experience of propulsion tests. The method gives power reduction for the selected bulb or suitable bulb design for a selected power reduction. The Kracht method is more useful for nabla $(\nabla)$ sectioned bulbs. Sharma and Sha [17] developed a method of designing a bulb by combining Kracht [2] and Yim [13] methods, which are two famous theories accepted in the bulb design. The method can do optimization of bulb parameters for design speed. The method uses a reanalysis of an approximate linear theory with sheltering effect for resistance estimation, and re-correlation with statistical analysis via a non-linear multivariate regression analysis from existing literature and tank test results available in the public domain.

There are different discretization techniques to solve various problems at CFD. The Finite Volume Method (FVM), which is derived from the Finite Difference Method (FDM) formulation, is one of the most widely used methods in CFD. Because it gives good results in non-structural solution mesh as well as in structural solutions. It is developed by Godunov [18]. With evolving technology, turbulence models have been developed that can solve the flow around complex and large geometries such as ships. The RANS (Reynolds-Averaged Navier-Stokes) turbulence modeling techniques, which are a simpler approach than other turbulence models, are used to solve the flow around the ship. Generally in CFD, k- $\varepsilon$ models (Standard k- $\varepsilon$ model, Realizable k- $\varepsilon$ model, RNG k- $\varepsilon$ model) and $\mathrm{k}-\omega$ models are used from two-equation models at flow applications of around the ship. The Realizable k- $\varepsilon$ Model, which is the most developed version of the k- $\varepsilon$ model, was developed by Shih et al. [19].

The CFD study of bulb optimization started in the 1990s. A comparative study of alternative bulb varieties (elliptical, conical, spoon, improved) with the aid of CFD is presented by Stromgren [20]. Kim and Jang [21] studied the effect of bulb on wave characteristics with CFD. An optimization of the pressure distribution on the surface and the around Series 60 vessels with bulb is studied with CFD by Huang et al. [22]. Lee and Sarath [23] conducted bulb designs in different forms for 12500 TEU containers ships and tried to determine optimum bulb sizes with CFD. A bulb optimization of a 36-meter-long fishing boat 
was conducted to improve it hydrodynamically with CFD by Sarasquete et al. [24], and the results of CFD analyses were compared with the data of the model resistance tests. A numerical procedure, which based on the genetic algorithm and a potential flow solver, for hydrodynamic optimization of a ship hull form with a bulbous bow has been established by Matulja and Dejhalla [25]. Chrismianto and Kim [26] used a cubic Bezier curvature and curve-plane intersection methods to design a bulb for the KRISO container ship model, based on 4 design parameters. The resistance values, which were obtained by the CFD analyses, were compared with the model data, and the accuracy of the analyses was confirmed.

The aim of the study is to determine which type of bulb on the fishing boats will be more effective in reducing total resistance. For this purpose, Delta $(\Delta)$, Nabla $(\nabla)$ and Elliptic (O) sectioned bulbs are added to the forms of 148/3, 148/4, 148/8 and 148/9 coded boats from ITU Fishing Boats Series. The designs of the forms with bulbs have been made. Firstly, Froude [27] and Hughes [28] method are used to calculate the total resistance of the full-scale boat from the model test data. Secondly, the results, which are obtained by CFD analyses, are compared with the test results. Then, CFD analyses of boat forms with bulbs are made. After that, the total resistance values, which are obtained from the CFD analyses, are compared with each other. Finally, the inferences, which are obtained in the study, are assessed according to ship codes, $\mathrm{C}_{\mathrm{B}}$, L/B ratio and bulb types. In this way, it has been determined which type of bulb is more beneficial for the fishing boats.

\section{Ship, model and bulb geometry (characteristic features)}

In the study conducted, the ship forms were selected from the Fishing Boats Series of ITU. Because of requirement to obtain more suitable boat forms for waters of Turkey, these fishing boat forms were produced by Kafalı et al.[29]. Characteristic values of these fishing boat forms are given in Table 1. The characteristic values of the models of these fishing boats are given in Table 2. Fishing Boats Series of ITU has been concluded with the study named "Computer Aided Design of Fishing Boats Suitable for Turkish Waters" which are prepared by Aydin [30].

The effects of bulbs on resistance were examined for 148/1 coded model by Soylemez [31]. The bulbs were in the delta profile. They were named $A_{1}, A_{2}$ and $A_{3}$. The characteristics of the three bulbs are given in Table 3 .

Table 1 Some characteristics values of the developed fishing boat forms [32]

\begin{tabular}{|c|c|c|c|c|c|c|c|c|c|c|c|c|}
\hline $\begin{array}{c}\text { Boat } \\
\text { No. }\end{array}$ & $\begin{array}{c}\mathrm{L} \\
(\mathrm{m})\end{array}$ & $\begin{array}{c}\mathrm{B} \\
(\mathrm{m})\end{array}$ & $\begin{array}{c}\mathrm{T} \\
(\mathrm{m})\end{array}$ & $\mathrm{C}_{\mathrm{B}}$ & $\mathrm{C}_{\mathrm{M}}$ & $\mathrm{C}_{\mathrm{WP}}$ & $\mathrm{C}_{\mathrm{P}}$ & $\mathrm{L} / \mathrm{B}$ & $\mathrm{B} / \mathrm{T}$ & $\begin{array}{c}\mathrm{LCB} \\
(\mathrm{m}) \\
(+\mathrm{Aft})\end{array}$ & $\begin{array}{c}\mathrm{S}_{\mathrm{W}} \\
\left(\mathrm{m}^{2}\right)\end{array}$ & $\begin{array}{c}\Delta_{\mathrm{S}} \\
(\text { without } \\
\text { app. })\end{array}$ \\
\hline $148 / 1$ & 20.00 & 5.714 & 2.286 & 0.378 & 0.661 & 0.730 & 0.572 & 3.500 & 2.500 & 0.83 & 126.10 & 992.96 \\
\hline $148 / 2$ & 20.00 & 5.714 & 2.286 & 0.535 & 0.892 & 0.789 & 0.600 & 3.500 & 2.500 & 0.01 & 139.80 & 1405.38 \\
\hline $148 / 3$ & 20.00 & 5.714 & 2.286 & 0.406 & 0.668 & 0.727 & 0.608 & 3.500 & 2.500 & 0.80 & 125.00 & 1066.51 \\
\hline $148 / 4$ & 20.00 & 5.714 & 2.286 & 0.497 & 0.888 & 0.789 & 0.560 & 3.500 & 2.500 & 0.02 & 134.10 & 1305.56 \\
\hline $148 / 5$ & 20.00 & 5.714 & 2.286 & 0.444 & 0.720 & 0.745 & 0.617 & 3.500 & 2.500 & 0.63 & 131.00 & 1166.33 \\
\hline $148 / 6$ & 22.86 & 5.714 & 2.286 & 0.400 & 0.668 & 0.727 & 0.599 & 4.001 & 2.500 & 0.91 & 145.50 & 1201.01 \\
\hline $148 / 7$ & 22.86 & 5.714 & 2.286 & 0.491 & 0.888 & 0.789 & 0.553 & 4.001 & 2.500 & 0.02 & 152.50 & 1474.24 \\
\hline $148 / 8$ & 28.57 & 5.714 & 2.286 & 0.404 & 0.668 & 0.727 & 0.605 & 5.000 & 2.500 & 1.14 & 179.40 & 1516.01 \\
\hline $148 / 9$ & 28.57 & 5.714 & 2.286 & 0.493 & 0.888 & 0.789 & 0.555 & 5.000 & 2.500 & 0.03 & 190.80 & 1849.98 \\
\hline
\end{tabular}


Table 2 Some characteristics values of the models used in the tests [32]

\begin{tabular}{|c|c|c|c|c|c|c|c|c|c|c|c|c|}
\hline $\begin{array}{c}\text { Model } \\
\text { No. }\end{array}$ & $\begin{array}{c}\mathrm{L} \\
(\mathrm{m})\end{array}$ & $\begin{array}{c}\mathrm{B} \\
(\mathrm{m})\end{array}$ & $\begin{array}{c}\mathrm{T} \\
(\mathrm{m})\end{array}$ & $\mathrm{C}_{\mathrm{B}}$ & $\mathrm{C}_{\mathrm{M}}$ & $\mathrm{C}_{\mathrm{WP}}$ & $\mathrm{C}_{\mathrm{P}}$ & $\mathrm{L} / \mathrm{B}$ & $\mathrm{B} / \mathrm{T}$ & $\begin{array}{c}\text { LCB } \\
(\mathrm{m})\end{array}$ & $\begin{array}{c}\mathrm{S}_{\mathrm{W}} \\
\left(\mathrm{m}^{2}\right)\end{array}$ & $\begin{array}{c}\Delta_{\mathrm{m}} \\
(\mathrm{kN})\end{array}$ \\
\hline 148/1B & 2.000 & 0.571 & 0.229 & 0.378 & 0.661 & 0.730 & 0.572 & 3.500 & 2.500 & 0.083 & 1.261 & 0.968 \\
\hline 148/2B & 2.000 & 0.571 & 0.229 & 0.535 & 0.892 & 0.789 & 0.600 & 3.500 & 2.500 & 0.001 & 1.398 & 1.370 \\
\hline 148/3B & 2.000 & 0.571 & 0.229 & 0.406 & 0.668 & 0.727 & 0.608 & 3.500 & 2.500 & 0.080 & 1.250 & 1.039 \\
\hline 148/4B & 2.000 & 0.571 & 0.229 & 0.497 & 0.888 & 0.789 & 0.560 & 3.500 & 2.500 & 0.002 & 1.341 & 1.272 \\
\hline 148/5B & 2.000 & 0.571 & 0.229 & 0.444 & 0.720 & 0.745 & 0.617 & 3.500 & 2.500 & 0.063 & 1.310 & 1.137 \\
\hline 148/6B & 2.286 & 0.571 & 0.229 & 0.400 & 0.668 & 0.727 & 0.599 & 4.001 & 2.500 & 0.091 & 1.455 & 0.171 \\
\hline 148/7B & 2.286 & 0.571 & 0.229 & 0.491 & 0.888 & 0.789 & 0.553 & 4.001 & 2.500 & 0.002 & 1.525 & 1.437 \\
\hline 148/8B & 2.857 & 0.571 & 0.229 & 0.404 & 0.668 & 0.727 & 0.605 & 5.000 & 2.500 & 0.114 & 1.794 & 1.478 \\
\hline 148/9B & 2.857 & 0.571 & 0.229 & 0.493 & 0.888 & 0.789 & 0.555 & 5.000 & 2.500 & 0.003 & 1.908 & 1.803 \\
\hline
\end{tabular}

Table 3 Properties of $A_{1}, A_{2}$ and $A_{3}$ bulbs [31]

\begin{tabular}{|c|l|l|c|}
\hline Bulb code & $\mathrm{b} / \mathrm{B}$ ratio & $1 / \mathrm{b}$ ratio & cross sectional area ratio \\
\hline $\mathrm{A}_{1}$ & $\frac{\mathrm{b}}{\mathrm{B}}=\frac{\mathrm{C}_{\mathrm{B}}}{2.5}$ & $\frac{1}{\mathrm{~b}}=1.2$ & 0.12 \\
\hline $\mathrm{A}_{2}$ & $\frac{\mathrm{b}}{\mathrm{B}}=\frac{\mathrm{C}_{\mathrm{B}}}{3.5}$ & $\frac{1}{\mathrm{~b}}=1.2$ & 0.09 \\
\hline $\mathrm{A}_{3}$ & $\frac{\mathrm{b}}{\mathrm{B}}=\frac{\mathrm{C}_{\mathrm{B}}}{4.5}$ & $\frac{1}{\mathrm{~b}}=1.2$ & 0.07 \\
\hline
\end{tabular}

1: length between the endpoint of bulb and the forward perpendicular b: width of the largest width of bulb

It was seen that the $A_{1}$ and $A_{2}$ bulbs started to become effective after the speed of 9 knots (Fn 0.331) while the $\mathrm{A}_{3}$ bulb started to become effective after the service speed of 10 knots (Fn 0.367), and the $A_{2}$ was more effective than the $A_{1}$ [31].

At the bulb application in 148/1 coded model, Soylemez [31] stated that the most effective bulb is $\mathrm{A}_{2}$. The maximum width of the bulb $\mathrm{A}_{2}$ is given by the equation_la and the maximum length of the bulb $\mathrm{A}_{2}$ from the fore peak by the equation_lb.

$$
\begin{gathered}
\frac{b}{B}=\frac{C_{B}}{3.5} \\
\frac{l}{b}=1.2
\end{gathered}
$$

The maximum widths and the maximum lengths of the bulbs of 148/3,148/4, 148/8 and $148 / 9$ coded boats are calculated by equation (1a) and equation (1b), respectively. The maximum bulb lengths of 148/8 and 148/9 coded boats are multiplied by the length correction coefficient $1.4285(28.57 / 20.00)$. The maximum widths and the maximum lengths of the bulbs are given in Table 4.

Table 4 Maximum widths and lengths of the bulbs

\begin{tabular}{|c|c|c|c|c|c|}
\hline & & $148 / 3$ & $148 / 4$ & $148 / 8$ & $148 / 9$ \\
\hline Maximum bulb width [mm] & b & 663 & 810 & 660 & 805 \\
\hline Maximum bulb length [mm] & 1 & 795 & 972 & 1131 & 1380 \\
\hline
\end{tabular}


Delta, nabla and elliptical bulb forms are designed for each fishing boat form according to the maximum width and length given in Table 4. All of the forms are modeled in the RhinoCeros program in three dimensions.

Forms of boats with bulb have been named for the purpose of making observations and comparisons easier to follow. The delta (D), nabla (N) and elliptical (E) bulb forms of 148/3, 148/4, 148/8 and 148/9 coded fishing boats are named 148/3-D, 148/3-N, 148/3-E, 148/4-D, 148/4-N, 148/4-E, 148/8-D, 148/8-N 148/8-E, 148/9-D, 148/9-N and 149/3-E, respectively.

The non-dimensional offset values of the delta, nabla and elliptical type bulbs are given in Table 5, Table 6 and Table 7, respectively. The displacements of all generated boats for use in $\mathrm{CDF}$ analyses are given in Table 8.

Table 5 Non-dimensional offset values of the delta type bulbs

\begin{tabular}{|c|c|c|c|c|c|c|c|c|c|c|c|c|}
\hline \multicolumn{2}{|c|}{} & $0.0 \mathrm{~T}$ & $0.1 \mathrm{~T}$ & $0.2 \mathrm{~T}$ & $0.3 \mathrm{~T}$ & $0.4 \mathrm{~T}$ & $0.5 \mathrm{~T}$ & $0.6 \mathrm{~T}$ & $0.7 \mathrm{~T}$ & $0.8 \mathrm{~T}$ & $0.9 \mathrm{~T}$ & $1.0 \mathrm{~T}$ \\
\hline \multirow{3}{*}{ 148/3-D D } & $b_{k}$ & 0.100 & 0.667 & 0.960 & 1.020 & 0.947 & 0.809 & 0.622 & 0.398 & 0.211 & 0.115 & 0.100 \\
\cline { 2 - 12 } & $l_{k}$ & 0.000 & 0.754 & 0.959 & 0.994 & 0.930 & 0.777 & 0.549 & 0.311 & 0.132 & 0.038 & 0.000 \\
\hline \multirow{2}{*}{ 148/4-D } & $b_{k}$ & 0.109 & 0.679 & 0.958 & 1.018 & 0.946 & 0.808 & 0.620 & 0.395 & 0.210 & 0.121 & 0.109 \\
\cline { 2 - 12 } & $l_{k}$ & 0.000 & 0.780 & 0.959 & 0.987 & 0.930 & 0.784 & 0.550 & 0.306 & 0.132 & 0.040 & 0.000 \\
\hline \multirow{2}{*}{ 148/8-D } & $b_{k}$ & 0.100 & 0.667 & 0.961 & 1.022 & 0.946 & 0.807 & 0.622 & 0.397 & 0.212 & 0.115 & 0.100 \\
\cline { 2 - 11 } & $l_{k}$ & 0.000 & 0.803 & 0.959 & 0.981 & 0.930 & 0.787 & 0.550 & 0.310 & 0.132 & 0.027 & 0.000 \\
\hline \multirow{2}{*}{ 148/9-D D } & $b_{k}$ & 0.109 & 0.681 & 0.962 & 1.016 & 0.947 & 0.808 & 0.621 & 0.395 & 0.211 & 0.122 & 0.109 \\
\cline { 2 - 10 } & $l_{k}$ & 0.000 & 0.837 & 0.959 & 0.974 & 0.930 & 0.799 & 0.550 & 0.294 & 0.132 & 0.046 & 0.000 \\
\hline
\end{tabular}

Table 6 Non-dimensional offset values of the nabla type bulbs

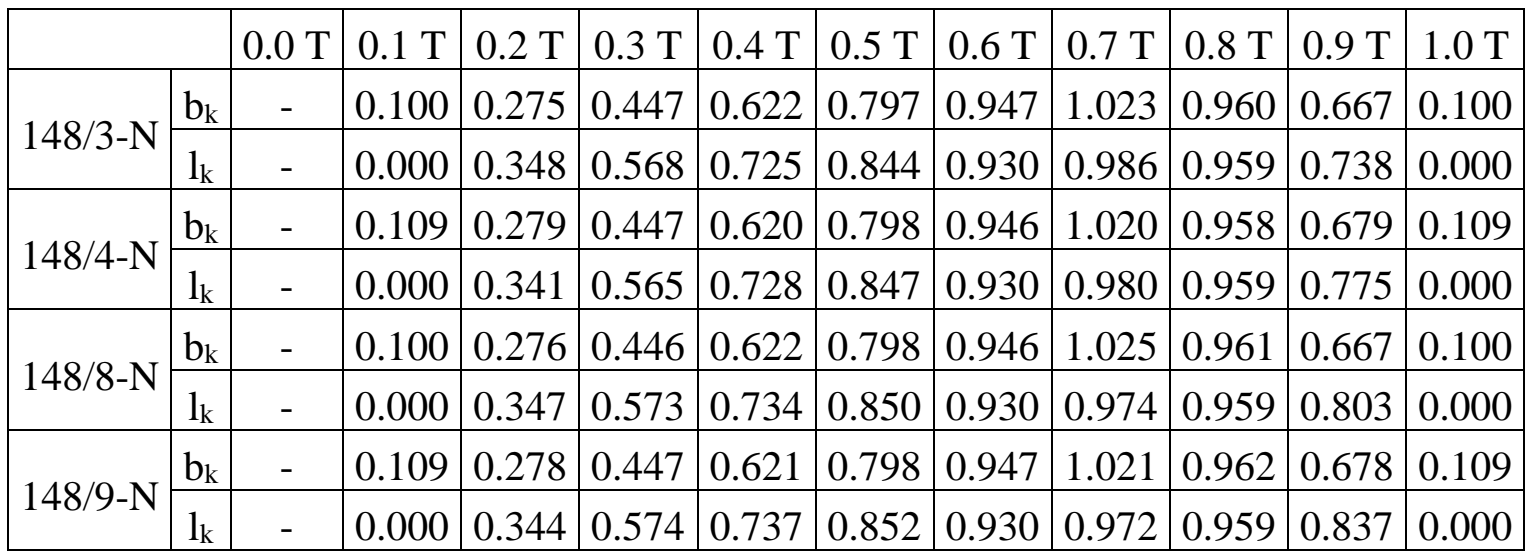

Table 7 Non-dimensional offset values of the elliptical type bulbs

\begin{tabular}{|c|c|c|c|c|c|c|c|c|c|c|c|c|}
\hline & & $0.0 \mathrm{~T}$ & $0.1 \mathrm{~T}$ & $0.2 \mathrm{~T}$ & $0.3 \mathrm{~T}$ & $0.4 \mathrm{~T}$ & $0.5 \mathrm{~T}$ & $0.6 \mathrm{~T}$ & $0.7 \mathrm{~T}$ & $0.8 \mathrm{~T}$ & $0.9 \mathrm{~T}$ & $1.0 \mathrm{~T}$ \\
\hline \multirow{2}{*}{$148 / 3-\mathrm{E}$} & $b_{k}$ & 0.100 & 0.428 & 0.679 & 0.854 & 0.960 & 0.996 & 0.960 & 0.854 & 0.679 & 0.428 & 0.100 \\
\hline & $l_{\mathrm{k}}$ & 0.000 & 0.546 & 0.749 & 0.879 & 0.959 & 0.989 & 0.959 & 0.856 & 0.676 & 0.407 & 0.000 \\
\hline \multirow{2}{*}{ 148/4-E } & $b_{k}$ & 0.109 & 0.437 & 0.682 & 0.855 & 0.958 & 0.993 & 0.958 & 0.855 & 0.682 & 0.437 & 0.109 \\
\hline & $l_{\mathrm{k}}$ & 0.000 & 0.536 & 0.745 & & & 0.988 & 0.959 & & & 0.431 & 0.000 \\
\hline \multirow{2}{*}{ 148/8-E } & $b_{k}$ & 0.100 & 0.431 & 0.679 & 0.855 & 0.961 & 0.995 & 0.961 & & 0.679 & 0.431 & 0.100 \\
\hline & $l_{\mathrm{k}}$ & 0.000 & 0.533 & 0.746 & 0.881 & 0.959 & 0.984 & 0.959 & 0.871 & 0.712 & 0.456 & 0.000 \\
\hline \multirow{2}{*}{ 148/9-E } & $b_{k}$ & 0.109 & 0.437 & 0.683 & 0.857 & 0.962 & 0.994 & 0.962 & 0.857 & 0.683 & 0.437 & 0.109 \\
\hline & $l_{\mathrm{k}}$ & 0.000 & 0.547 & 0.760 & 0.889 & 0.959 & 0.981 & 0.959 & 0.884 & 0.741 & 0.499 & 0.000 \\
\hline
\end{tabular}


Table 8 The displacements of all generated boats

\begin{tabular}{|l|l|l|l|l|l|l|l|}
\hline Boat No. & $\Delta_{\mathrm{S}}[\mathrm{kN}]$ & Boat No. & $\Delta_{\mathrm{S}}[\mathrm{kN}]$ & Boat No. & $\Delta_{\mathrm{S}}[\mathrm{kN}]$ & Boat No. & $\Delta_{\mathrm{S}}[\mathrm{kN}]$ \\
\hline $148 / 3$ & 1065.55 & $148 / 4$ & 1304.79 & $148 / 8$ & 1515.93 & $148 / 9$ & 1848.77 \\
\hline $148 / 3-\mathrm{D}$ & 1082.19 & $148 / 4-\mathrm{D}$ & 1319.21 & $148 / 8-\mathrm{D}$ & 1538.25 & $148 / 9-\mathrm{D}$ & 1870.26 \\
\hline $148 / 3-\mathrm{N}$ & 1082.02 & $148 / 4-\mathrm{N}$ & 1319.14 & $148 / 8-\mathrm{N}$ & 1538.13 & $148 / 9-\mathrm{N}$ & 1870.18 \\
\hline $148 / 3-\mathrm{E}$ & 1082.33 & $148 / 4-\mathrm{E}$ & 1319.46 & $148 / 8-\mathrm{E}$ & 1538.47 & $148 / 9-\mathrm{E}$ & 1870.36 \\
\hline
\end{tabular}

As an example, the lines plan of 148/3 coded fishing boat is shown in Figure 2. The fore cross sections plan and bulb profile are shown in Figure 3, Figure 4 and Figure 5 for 148/3-D, 148/3-N and 148/3-E coded fishing boat, respectively. The three-dimensional models of all generated fishing boat forms are shown in Figure 6.

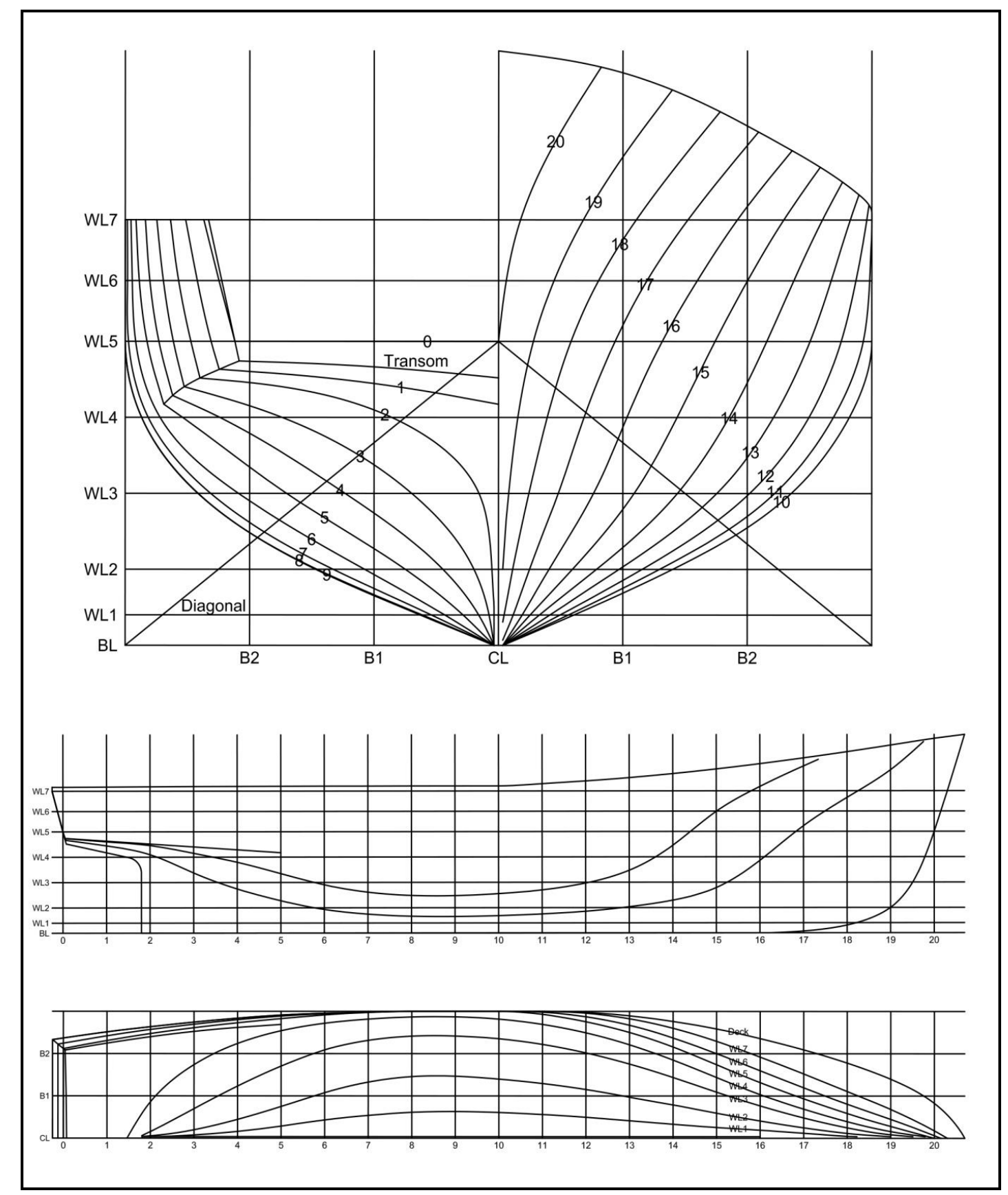

Fig. 2 Lines plan of the 148/3 coded fishing boat [29] 


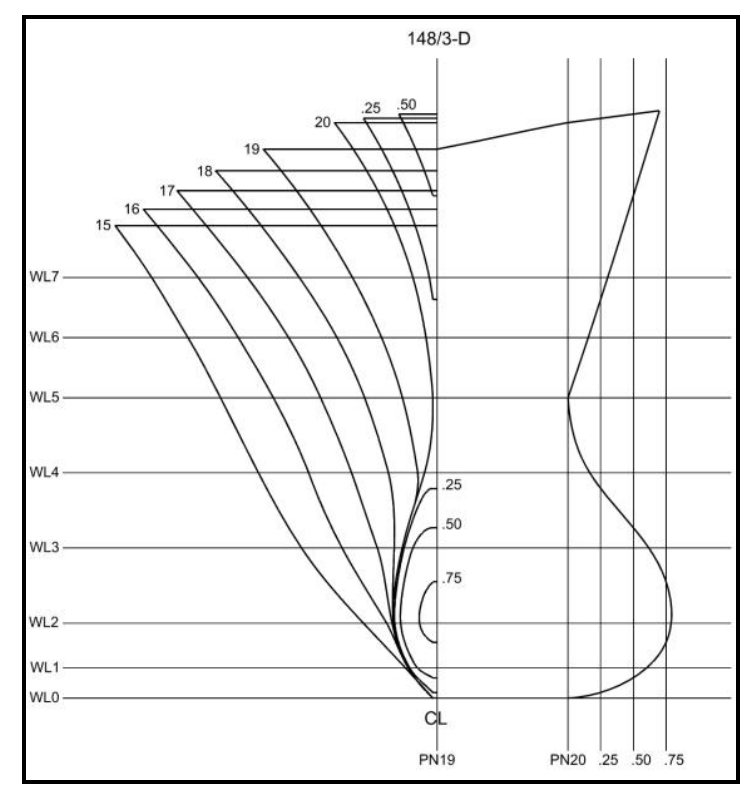

Fig. 3 Fore cross sections plan and bulb profile of the 148/3-D code fishing boat

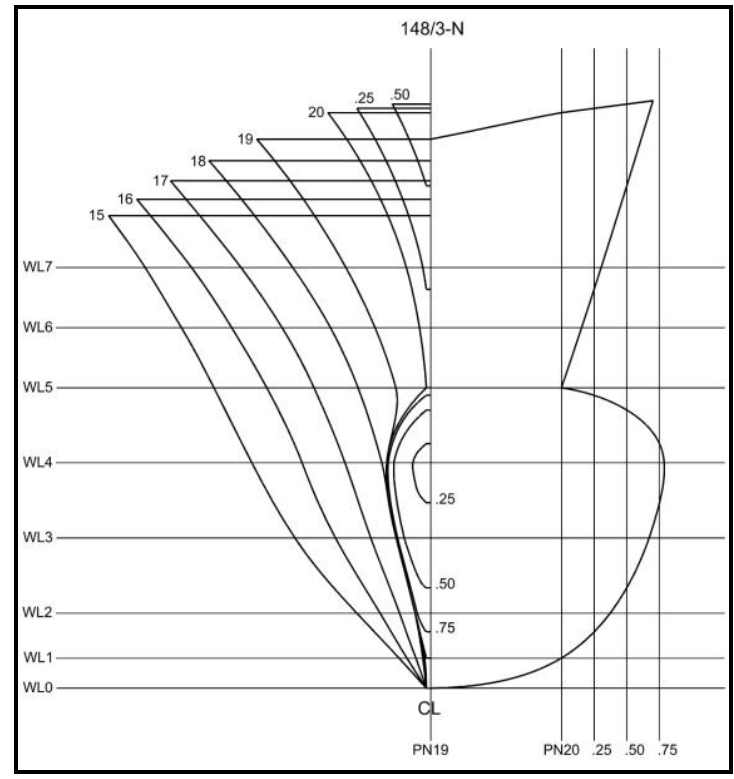

Fig. 4 Fore cross sections plan and bulb profile of the 148/3-N code fishing boat

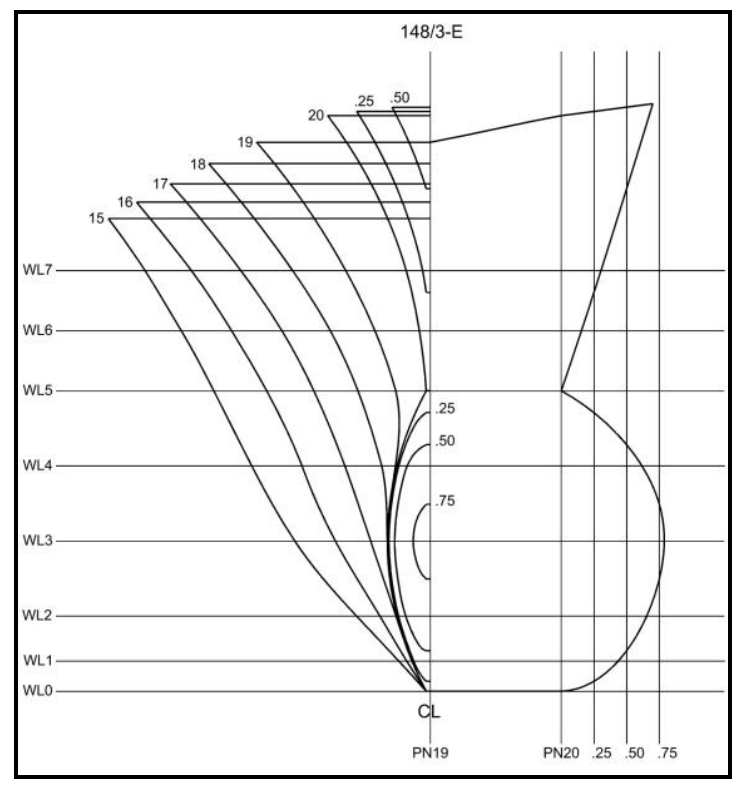

Fig. 5 Fore cross sections plan and bulb profile of the 148/3-E code fishing boat

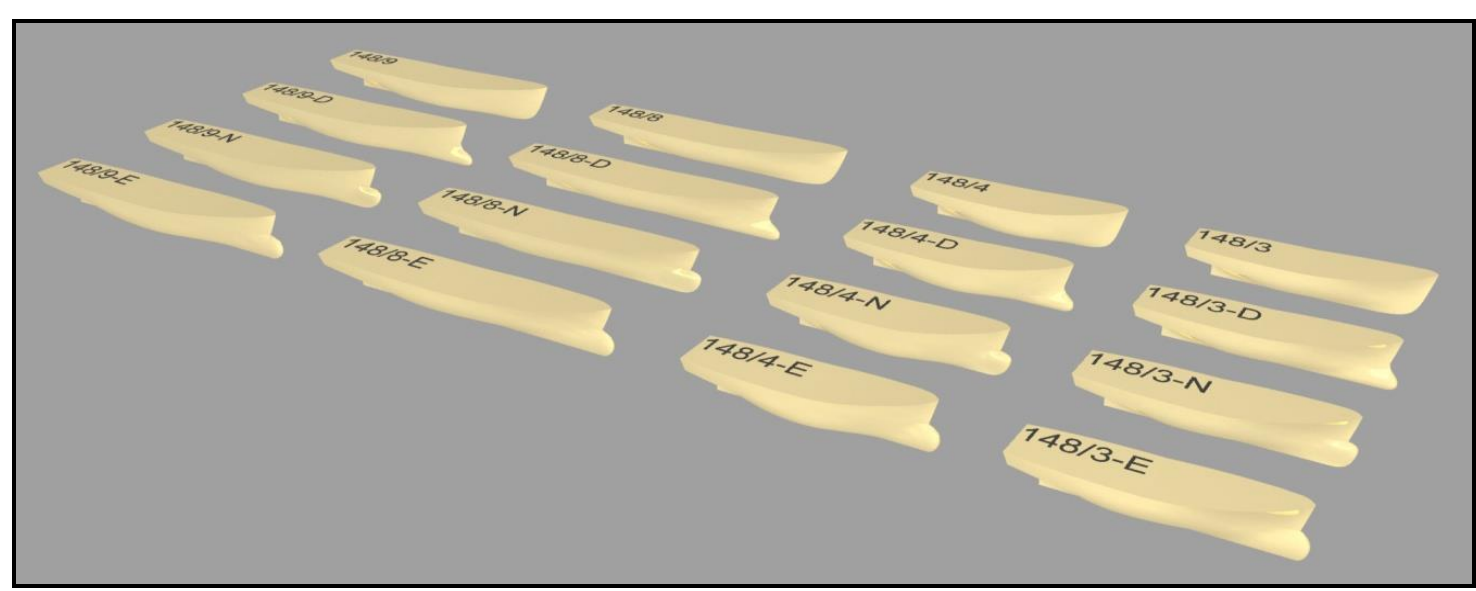

Fig. 6 Three dimensional models of fishing boats 


\section{Numerical modelling}

\subsection{Governing equations}

In this study, an Unsteady Reynolds-Averaged Navier-Stokes (URANS) method is used to solve the governing equations. These mass and momentum conservation equations are solved by the commercial CFD software STAR-CCM+. The averaged continuity and momentum equations for incompressible flows are given in tensor notation and Cartesian coordinates by equation_2 and equation_3.

$$
\begin{aligned}
& \frac{\partial\left(\rho \bar{u}_{i}\right)}{\partial x_{i}}=0 \\
& \frac{\partial\left(\rho \bar{u}_{i}\right)}{\partial t}+\frac{\partial}{\partial x_{j}}\left(\rho \bar{u}_{i} \bar{u}_{j}+\rho{\overline{u_{i}^{\prime} u^{\prime}}}_{j}\right)=-\frac{\partial \bar{p}}{\partial x_{i}}+\frac{\partial\left(\rho \bar{\tau}_{i j}\right)}{\partial x_{j}}
\end{aligned}
$$

where $\rho$ is density, $\bar{u}_{i}$ is the averaged Cartesian components of the velocity vector, $\rho \overline{u_{i}^{\prime} u^{\prime}}{ }_{j}$ is the Reynolds stresses and $\mathrm{p}$ is the mean pressure. $\bar{\tau}_{\mathrm{ij}}$ is the mean viscous stres tensor components, as shown in equation_4.

$$
\bar{\tau}_{i j}=\mu\left(\frac{\partial \bar{u}_{i}}{\partial x_{j}}+\frac{\partial \bar{u}_{j}}{\partial x_{i}}\right)
$$

in which $\mu$ is the dynamic viscosity.

\subsection{Turbulence model}

The "Realizable $k-\varepsilon$ Model" developed by Shih et al. [19] is the most advanced version of the $k-\varepsilon$ model.

There are two basic differences from the standard $k-\varepsilon$ model. The first is that the model contains a new transport equation for the turbulence loss rate $\varepsilon$. Second, $C_{\mu}$, a critical coefficient of the model, is expressed as a function of the mean flow and turbulence properties rather than being fixed as in the standard model. The understanding of an $C_{\mu}$ variable is also compatible with the experimental data in boundary layer.

Shih et al. [19] developed transport equations are as follows:

$$
\begin{gathered}
\frac{\partial}{\partial t}(\rho k)+\frac{\partial}{\partial x_{j}}\left(\rho k u_{j}\right)=\frac{\partial}{\partial x_{j}}\left[\left(\mu+\frac{\mu_{t}}{\sigma_{k}}\right) \frac{\partial k}{\partial x_{j}}\right]+G_{k}+G_{b}-\rho \varepsilon-Y_{M}+S_{K} \\
\frac{\partial}{\partial t}(\rho \varepsilon)+\frac{\partial}{\partial x_{j}}\left(\rho \varepsilon u_{j}\right)=\frac{\partial}{\partial x_{j}}\left[\left(\mu+\frac{\mu_{t}}{\sigma_{\varepsilon}}\right) \frac{\partial \varepsilon}{\partial x_{j}}\right]+\rho C_{1} S_{\varepsilon} \\
-\rho C_{2} \frac{\varepsilon^{2}}{k+\sqrt{v \varepsilon}}+C_{1 \varepsilon} \frac{\varepsilon}{k} C_{3 \varepsilon} G_{b}+S_{\varepsilon}
\end{gathered}
$$


In this equation $G_{k}$ is the turbulent kinetic energy production due to the average velocity gradients, $G_{b}$ is the production of turbulence kinetic energy depending on the density changes due to temperature differences, $Y_{M}$ constrictive turbulence shows the effect of the expansion in the turbulence to the whole spread. The terms $S_{K}$ and $S_{\varepsilon}$ are user-defined source terms.

\subsection{Performing resistance analyses using the CFD method}

Star-CCM+ software calculates the total force on the surface; Normal and tangential forces, i.e., pressure and friction (shear) forces [33].

The force on a surface is computed as:

$$
f=\sum_{f}\left(f_{f}^{\text {pressure }}+f_{f}^{\text {shear }}\right) \cdot n_{f}
$$

where $f_{f}^{\text {pressure }}$ and $f_{f}^{\text {shear }}$ are the pressure and shear force vectors on the surface face $f$, and $n_{f}$ is a user-specified direction vector that indicates the direction in which the force should be computed.

\section{Test results}

In this study, 148/3, 148/4, 148/8 and 148/9 coded models from ITU Fishing Boats Series hull forms, which carried out model tests by Kafalı et al. [29], are examined. The information of the models and test conditions are given in Table 9. The characteristics of seawater and test basin water are given in Table 10. The results of the resistance tests of the models are given in Table 11.

Table 9 Model information and test conditions [29]

\begin{tabular}{|c|c|c|c|c|c|}
\hline \multicolumn{2}{|c|}{ Model No. } & $148 / 3 \mathrm{~B}$ & $148 / 4 \mathrm{~B}$ & $148 / 8 \mathrm{~B}$ & $148 / 9 \mathrm{~B}$ \\
\hline \multicolumn{2}{|c|}{ Date of test } & 10.4 .1978 & 26.4 .1978 & 16.10 .1978 & 8.11 .1978 \\
\hline Geometrical similarity ratio & $\alpha$ & 10 & 10 & 10 & 10 \\
\hline Length of Waterline & $\mathrm{LwL}[\mathrm{m}]$ & 2.000 & 2.000 & 2.857 & 2.857 \\
\hline Length Between Perpendiculars & $\mathrm{LPP}[\mathrm{m}]$ & 2.000 & 2.000 & 2.857 & 2.857 \\
\hline Draught & $\mathrm{T}[\mathrm{m}]$ & 0.229 & 0.229 & 0.229 & 0.229 \\
\hline Wet Surface Area & $\mathrm{S}\left[\mathrm{m}^{2}\right]$ & 1.250 & 1.341 & 1.794 & 1.908 \\
\hline Displacement Force & $\Delta_{\mathrm{m}}[\mathrm{kN}]$ & 1.039 & 1.272 & 1.478 & 1.803 \\
\hline Basin Water Temperature & $\mathrm{t}\left[{ }^{\circ} \mathrm{C}\right]$ & 16.00 & 16.00 & 18.00 & 16.50 \\
\hline Form Factor & $\mathrm{k}$ & 0.518 & 0.554 & 0.281 & 0.296 \\
\hline
\end{tabular}

Table 10 Properties of freshwater and seawater [34]

\begin{tabular}{|c|c|c|c|c|c|}
\hline \multicolumn{2}{|l|}{} & Freshwater & Freshwater & Freshwater & Seawater \\
\hline Temperature $(\mathrm{t})$ & {$\left[{ }^{\circ} \mathrm{C}\right]$} & 16.0 & 16.5 & 18.0 & 15.0 \\
\hline Mass density $(\rho)$ & {$\left[\mathrm{kg} / \mathrm{m}^{3}\right]$} & 998.9461 & 998.8634 & 998.5986 & 1026.0210 \\
\hline Kinematic viscosity $(\mathrm{v})$ & {$\left[\mathrm{m}^{2} / \mathrm{s}\right]$} & $1.1093 \mathrm{E}-06$ & $1.0950 \mathrm{E}-06$ & $1.0542 \mathrm{E}-06$ & $1.1892 \mathrm{E}-06$ \\
\hline Dynamic viscosity $(\mu)$ & {$[\mathrm{Pa} . \mathrm{s}]$} & 0.001108 & 0.001094 & 0.001053 & 0.001220 \\
\hline
\end{tabular}


Table 11 Model resistance test data

\begin{tabular}{|c|c|c|c|c|c|c|c|}
\hline \multicolumn{2}{|c|}{$148 / 3 \mathrm{~B}$} & \multicolumn{2}{c|}{$148 / 4 \mathrm{~B}$} & \multicolumn{2}{c|}{$148 / 8 \mathrm{~B}$} & \multicolumn{2}{c|}{$148 / 9 \mathrm{~B}$} \\
\hline $\mathrm{V}_{\mathrm{m}}[\mathrm{m} / \mathrm{s}]$ & $\mathrm{R}_{\mathrm{Tm}}[\mathrm{kgf}]$ & $\mathrm{V}_{\mathrm{m}}[\mathrm{m} / \mathrm{s}]$ & $\mathrm{R}_{\mathrm{Tm}}[\mathrm{kgf}]$ & $\mathrm{V}_{\mathrm{m}}[\mathrm{m} / \mathrm{s}]$ & $\mathrm{R}_{\mathrm{Tm}}[\mathrm{kgf}]$ & $\mathrm{V}_{\mathrm{m}}[\mathrm{m} / \mathrm{s}]$ & $\mathrm{R}_{\mathrm{Tm}}[\mathrm{kgf}]$ \\
\hline 0.25 & 0.0305 & 0.25 & 0.0330 & 0.25 & 0.0355 & 0.25 & 0.0365 \\
\hline 0.50 & 0.1065 & 0.50 & 0.1150 & 0.50 & 0.1210 & 0.50 & 0.1260 \\
\hline 0.75 & 0.2310 & 0.75 & 0.2575 & 0.75 & 0.2600 & 0.75 & 0.2695 \\
\hline 1.00 & 0.4150 & 1.00 & 0.5000 & 1.00 & 0.4640 & 1.00 & 0.4950 \\
\hline 1.25 & 0.6605 & 1.25 & 0.9850 & 1.30 & 0.7950 & 1.30 & 1.0250 \\
\hline 1.50 & 1.1150 & 1.50 & 1.8700 & 1.60 & 1.3125 & 1.60 & 1.9000 \\
\hline 1.70 & 2.2360 & 1.70 & 3.4500 & 2.00 & 3.0500 & 1.95 & 4.0000 \\
\hline
\end{tabular}

The total resistance values of the full-scale boats are calculated by the methods of Froude [27] and Hughes [28] from the model resistance test data. The total resistance values, which are calculated by the Froude method for 148/3, 148/4, 148/8 and 148/9 coded boats, are given in Table 12. The total resistance values, which are calculated by the Hughes method, are given in Table 13.

Table 12 Total resistance values obtained by Froude method

\begin{tabular}{|c|c|c|c|c|c|c|c|}
\hline \multicolumn{2}{|c|}{$148 / 3$} & \multicolumn{2}{c|}{$148 / 4$} & \multicolumn{2}{c|}{$148 / 8$} & \multicolumn{2}{c|}{$148 / 9$} \\
\hline Fn & $\mathrm{R}_{\mathrm{Ts}}[\mathrm{kN}]$ & Fn & $\mathrm{R}_{\mathrm{Ts}}[\mathrm{kN}]$ & Fn & $\mathrm{R}_{\mathrm{Ts}}[\mathrm{kN}]$ & Fn & $\mathrm{R}_{\mathrm{Ts}}[\mathrm{kN}]$ \\
\hline 0.056 & 0.1966 & 0.056 & 0.2166 & 0.047 & 0.2186 & 0.047 & 0.2170 \\
\hline 0.113 & 0.7126 & 0.113 & 0.7720 & 0.094 & 0.7627 & 0.094 & 0.7752 \\
\hline 0.169 & 1.6039 & 0.169 & 1.8182 & 0.142 & 1.6997 & 0.142 & 1.7191 \\
\hline 0.226 & 2.9919 & 0.226 & 3.7615 & 0.189 & 3.1587 & 0.189 & 3.3454 \\
\hline 0.282 & 4.9033 & 0.282 & 8.0444 & 0.246 & 5.6142 & 0.246 & 7.7329 \\
\hline 0.339 & 8.8286 & 0.339 & 16.2584 & 0.302 & 9.7795 & 0.302 & 15.4127 \\
\hline 0.384 & 19.5344 & 0.384 & 31.5449 & 0.378 & 25.6370 & 0.368 & 35.0224 \\
\hline
\end{tabular}

Table 13 The total resistance values obtained by the Hughes method

\begin{tabular}{|c|c|c|c|c|c|c|c|}
\hline \multicolumn{2}{|c|}{$148 / 3$} & \multicolumn{2}{c|}{$148 / 4$} & \multicolumn{2}{c|}{$148 / 8$} & \multicolumn{2}{c|}{$148 / 9$} \\
\hline Fn & $\mathrm{R}_{\mathrm{Ts}}[\mathrm{kN}]$ & Fn & $\mathrm{R}_{\mathrm{Ts}}[\mathrm{kN}]$ & Fn & $\mathrm{R}_{\mathrm{Ts}}[\mathrm{kN}]$ & Fn & $\mathrm{R}_{\mathrm{Ts}}[\mathrm{kN}]$ \\
\hline 0.056 & 0.1572 & 0.056 & 0.1705 & 0.047 & 0.1985 & 0.047 & 0.1932 \\
\hline 0.113 & 0.5844 & 0.113 & 0.6220 & 0.094 & 0.6969 & 0.094 & 0.6972 \\
\hline 0.169 & 1.3465 & 0.169 & 1.5171 & 0.142 & 1.5669 & 0.142 & 1.5621 \\
\hline 0.226 & 2.5688 & 0.226 & 3.2666 & 0.189 & 2.9398 & 0.189 & 3.0866 \\
\hline 0.282 & 4.2803 & 0.282 & 7.3157 & 0.246 & 5.2683 & 0.246 & 7.3240 \\
\hline 0.339 & 7.9732 & 0.339 & 15.2579 & 0.302 & 9.2822 & 0.302 & 14.8248 \\
\hline 0.384 & 18.4706 & 0.384 & 30.3005 & 0.378 & 24.9015 & 0.368 & 34.1909 \\
\hline
\end{tabular}




\section{Method of calculation}

\subsection{Boundary conditions}

In this study, the dimensions of the calculation volume were determined with reference to the recommended dimensions for the flow problems around the ship, and the recommended dimensions were taken from the manual of the CFD program [33].

The computational domain is dimensioned according to the LBP (the length between the fore and the aft perpendiculars of the ship) with reference to the intersection of aft perpendicular and loaded water line of the ship as shown in Figure 7. The volume of control was selected to be of rectangular prism. The dimension of the computational domain is $100 \times 50 \times 75 \mathrm{~m}$ for $148 / 3$ and $148 / 4$ coded boats. $143 \times 72 \times 107 \mathrm{~m}$ is the dimension of the computational domain for $148 / 8$ and $148 / 9$ coded boats.

As shown in Figure 7, the surfaces of the rectangular prism, which defines boundaries in the computational domain, are named Inlet, Outlet, Top, Bottom, Symmetry and Side. The surfaces, which are represented the ship form, are named Hull.

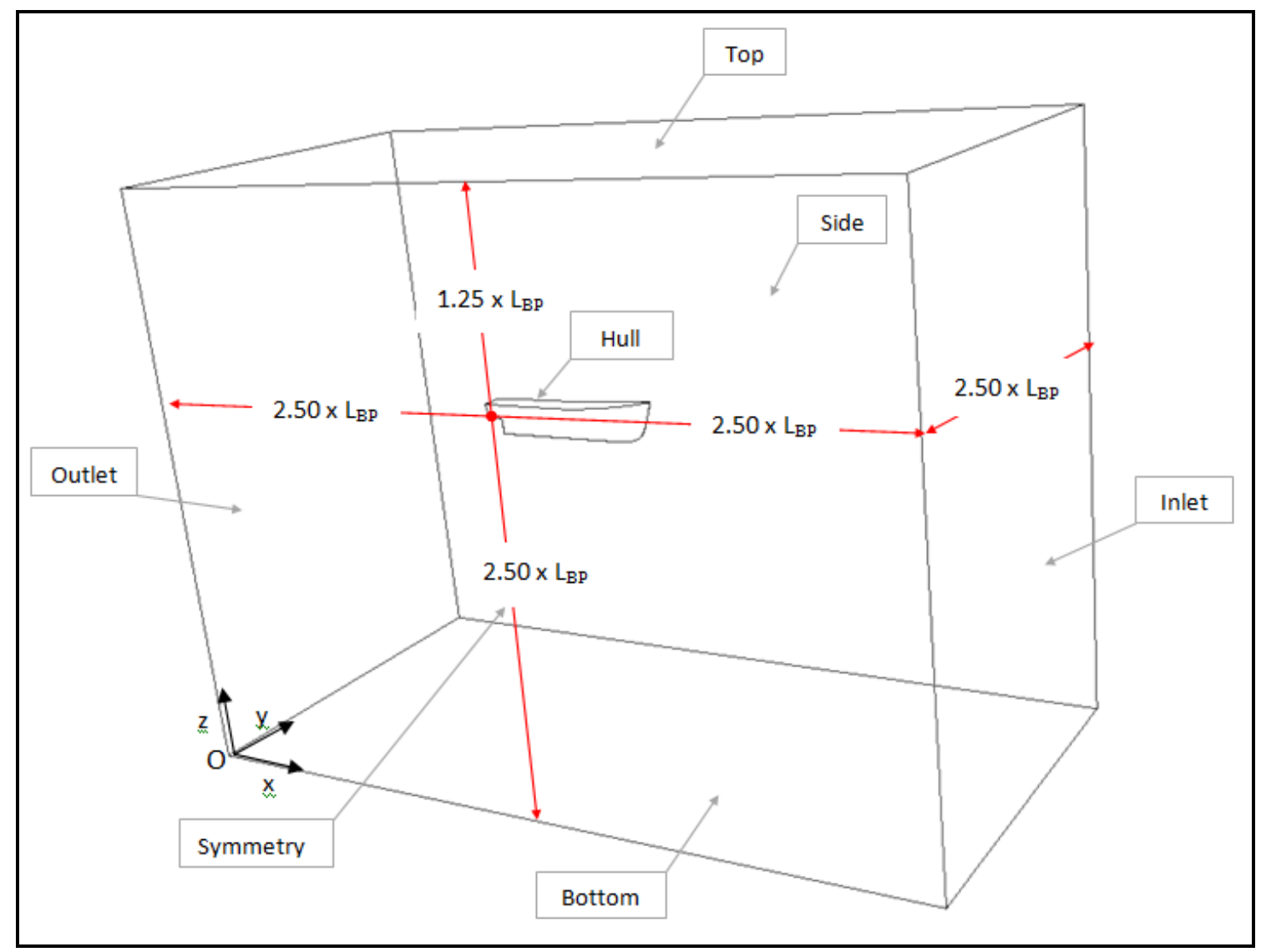

Fig. 7 The dimensions of the computational domain and the names of the surfaces

The boundary conditions of the regions called Inlet, Outlet, Top, Bottom, Symmetry, Side and Boat in Figure 7 are given in Table 14.

The velocity inlet is defined as boundary condition for Inlet, because the flow enters the computational domain on the -x direction. At the Top, Bottom and Side borders, the flow velocity is equal to the potential flow, so the boundary condition is equivalent to the velocity inlet boundary condition. The symmetry plane boundary condition is used to indicate that symmetry of the computational domain is also on the other side of the Symmetry boundary. As a result of the events occurring within the computational domain, the boundary condition 
of Outlet is selected the pressure outlet, because the values such as speed, pressure are not known at the boundary. The wall is assigned to the Hull as boundary condition, and it is assumed that the flow velocity components on the ship surface are zero (no-slip boundary condition).

Table 14 Boundary conditions

\begin{tabular}{|c|c|}
\hline Boundary Name & Boundary Condition \\
\hline Inlet & Velocity Inlet \\
\hline Outlet & Pressure Outlet \\
\hline Top & Velocity Inlet \\
\hline Bottom & Velocity Inlet \\
\hline Symmetry & Symmetry Plane \\
\hline Side & Velocity Inlet \\
\hline Hull & Wall \\
\hline
\end{tabular}

\subsection{Design of mesh structure}

In this study, the rectangular prismatic mesh structure is chosen because it gives better results than other mesh structures at the free water surface flow.

An average of 600 thousand, 1.2 million, 2.8 million, 3.7 million, 4.7 million and 7.4 million cells were created in the computational domains. It has been found that the resistance values, which are obtained in mesh structures with over 2.8 million cells, have not changed or that the change has not had much effect on the solution. For this reason, the CFD calculations are made with an average of 2.8 million cells and 8.6 million surfaces for 148/3, 148/3-D, 148/3-N, 148/3-E, 148/4, 148/4-D, 148/4-N and 148/4-E coded fishing boats. The CFD calculations are made with an average of 3.8 million cells and 11.4 million surfaces for $148 / 8$, 148/8-D, 148/8-N, 148/8-E, 148/9, 148/9-D, 148/9-N and 148/9-E coded fishing boats.

The mesh structure is produced for 112 computational domains. As an example, the mesh structure of the 148/3 coded boat is shown in Figure 8 and Figure 9.

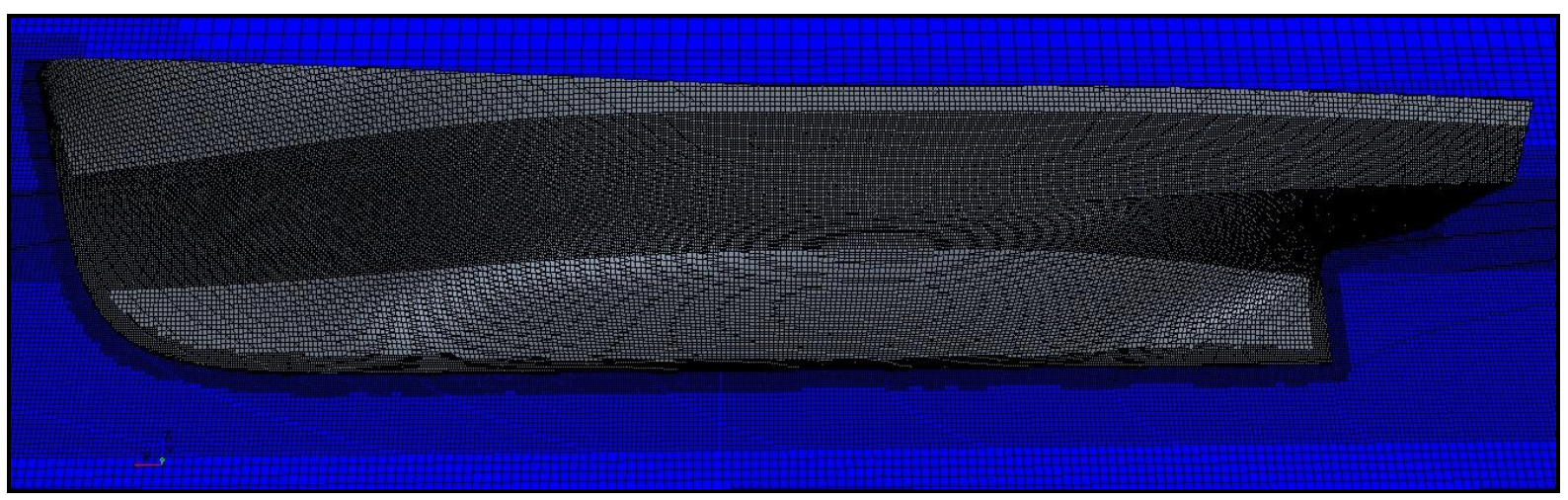

Fig. 8 Boat surface mesh structure 


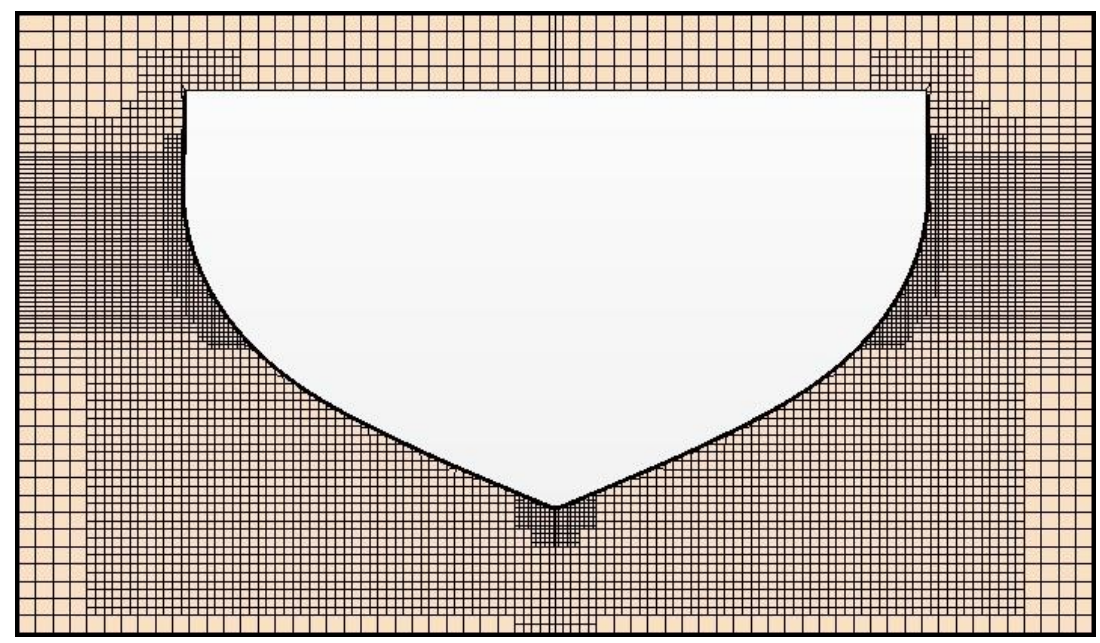

Fig. 9 Boat cross section mesh structure

\subsection{Solution method}

After the mesh structure was established, the physical conditions were determined. The solution model is modeled in a 2-phase fluid environment (seawater and air) as in the real environment, and the loaded waterline of fishing boat is free water surface. The physical properties of seawater and air, which is used in calculations, are given in Table 15.

Table 15 Physical properties of seawater and air

\begin{tabular}{|c|c|c|c|}
\hline \multicolumn{2}{|l|}{} & Seawater & Air \\
\hline Mass density $(\rho)$ & {$\left[\mathrm{kg} / \mathrm{m}^{3}\right]$} & 1026.02100 & 1.18415 \\
\hline Dynamic viscosity $(\mu)$ & {$[$ Pa.s $]$} & $1.220 \times 10^{-3}$ & $1.855 \times 10^{-5}$ \\
\hline
\end{tabular}

The value of gravity acceleration (gravity) is entered as $9.8067 \mathrm{~m} / \mathrm{s}^{2}$ in the direction of $\mathrm{z}$ axis in order to be able to create a gravitational effect on the computational domain as in the world.

The VOF (Volume of Fluid) method is chosen as the surface capture method because of the effects of free surface water. The VOF method is included the effects of free surface water in the analyses. The results of total resistance can be obtained more accurately via this method. It was developed by Hirt and Nichols [35]. It gives accurate results in high degree nonlinear free surface problems such as wave breaks. In addition, this method is preferred for calculations of ship wave because it provides flexibility and convenience in mesh production.

The implicit unsteady is chosen as the computation time in order to avoid the timedependent interactions of the phases and increasing the accuracy rates of the results. Realizable k- $\varepsilon$ Model is chosen as the turbulent flow model. Segregated Flow is chosen as the solution algorithm because it provides ideal results in incompressible and multiphase flows.

The implicit unsteady is selected as the calculation time. The time step of the solution for each analysis is calculated according to equation_8 [36]. In this equation $U$ is the velocity, $\Delta \mathrm{t}$ is the time step, and $\Delta \mathrm{x}$ is the minimum mesh cell length. As a result of various assays, the value of Courant-Friedrichs-Lewy (CFL) is set at 5. The determined time steps with physical time, number of iteration and computation time, approximately, are given in Table 16.

$$
C F L=\frac{U \Delta t}{\Delta x}
$$


Table 16 Time steps of the solver, physical time, number of iteration and computation time

\begin{tabular}{|c|c|c|c|c|c|}
\hline $\begin{array}{c}\text { 148/3, D, N, E } \\
\text { 148/4, D, N, E }\end{array}$ & $\begin{array}{c}\text { 148/8, D, N, E } \\
\text { 148/9, D, N, E }\end{array}$ & Time Step & Physical Time & \multirow{2}{*}{$\begin{array}{c}\text { Number of } \\
\text { Iteration }\end{array}$} & Computation Time \\
\cline { 1 - 1 } Fn & Fn & & [second] & & [hour] \\
\hline 0.056 & 0.047 & 0.150 & 100 & 6000 & 10 \\
\hline 0.113 & 0.094 & 0.080 & 150 & 16000 & 18 \\
\hline 0.169 & 0.142 & 0.050 & 200 & 40000 & 40 \\
\hline 0.226 & 0.189 & 0.040 & 250 & 60000 & 120 \\
\hline 0.282 & 0.246 & 0.030 & 350 & 120000 & 192 \\
\hline 0.339 & 0.302 & 0.025 & 300 & 120000 & 240 \\
\hline 0.384 & 0.378 & 0.020 & 300 & 160000 & 288 \\
\hline
\end{tabular}

In this study, the maximum number of internal iterations for the each time step is 10 . CFD analyses are made at different speeds. Implicit unsteady flow is defined in the CFD program. Therefore, it would be wrong to evaluate for convergence criteria according to the convergence of residues or a fixed physical time. Considering that the CFD analyzes are consistent with the test values, the convergence criteria for the CFD analyses is accepted that the change in values after a certain number of iterations is below 0.01 at low speeds and below 0.1 at high speeds.

The total resistance values vary depending on the physical time due to the fact that timedependent variable flow is defined in the CFD program. Therefore, the total resistance values, at which calculations are terminated, are not used to directly comparison. Depending on the physical time, at high speeds which the resistance value fluctuations are excessive, for more accurate result, ship length is divided by the speed at which the resistance is calculated. In this way, the duration of a flow particle to cross the length of the ship is found. And, the total physical time is divided into pieces according to this duration. The arithmetic mean of the last three total resistance values from the time of convergence of the solution is the final total resistance value for comparisons. Thus, both the accuracy of the convergence is controlled and the physical time-independent resistance values are obtained.

\section{Results and discussions}

Firstly, the total resistance values which are obtained by CFD analyses are compared with the total resistance values obtained from the Froude and Hughes methods. Then, the CFD results of boat forms with and without bulb are compared between themselves. Finally, it has been determined that which type of bulb is more beneficial for the fishing boats by taking into account the increase or decrease on the total resistance values of the forms.

\subsection{Comparison of CFD results with test results}

The CFD analyses are performed on Froude numbers which are determined for 148/3, 148/4, 148/8 and 148/9 coded boats. The compatibility of the CFD results and the test results is examined by comparing the ship total resistance values obtained from the CFD analyses with the ship total resistance values obtained from Froude and Hughes methods. The percentage difference between the CFD value and the Froude method value is found by the equation_9. The percentage difference between the CFD value and the Hughes method value is found by the equation_10. 


$$
\begin{aligned}
& \text { Difference Percentage }=\frac{\text { CFD Value }- \text { Froude Method Value }}{\text { Froude Method Value }} \text { X100 } \\
& \text { Difference Percentage }=\frac{\text { CFD Value }- \text { Hughes Method Value }}{\text { Hughes Method Value }} \text { X100 }
\end{aligned}
$$

According to Froude numbers, total resistance values, which are obtained from Froude and Hughes methods, and the difference percentages of CFD values than Froude method values, and the difference percentages of CFD values than Hughes method values are given in Table 17, 18, 19, 20 for 148/3, 148/4, 148/8, 148/9 coded boats, respectively.

As can be seen from Table 17, 18, 19 and 20, according to Froude method, the arithmetic mean value of the difference percentages is around $13 \%$ while according to Hughes method the average is about $4 \%$. When each analysis is evaluated in its own group, CFD results are more compatible with the total resistance values, which are obtained from the test data, at low speeds. It is also seen that the results on ships with low $C_{B}$ are more consistent than the results on ships with high $\mathrm{C}_{\mathrm{B}}$.

Table 17 The comparison between the total resistance values, which are obtained from Froude and Hughes

\begin{tabular}{|c|c|c|c|c|c|c|}
\hline \multicolumn{5}{|c|}{$148 / 3$} & \multicolumn{2}{|c|}{ Difference Percentages } \\
\hline \multirow[t]{2}{*}{ Fn } & \multirow{2}{*}{$\begin{array}{c}\mathrm{V}_{\mathrm{S}} \\
{[\mathrm{knot}]}\end{array}$} & $\begin{array}{l}\text { Froude } \\
\text { Method }\end{array}$ & $\begin{array}{l}\text { Hughes } \\
\text { Method }\end{array}$ & CFD & $\begin{array}{l}\text { According to } \\
\text { Froude Method }\end{array}$ & $\begin{array}{c}\text { According to } \\
\text { Hughes Method }\end{array}$ \\
\hline & & $\mathrm{R}_{\mathrm{T}}[\mathrm{kN}]$ & $\mathrm{R}_{\mathrm{T}}[\mathrm{kN}]$ & $\mathrm{R}_{\mathrm{T}}[\mathrm{kN}]$ & $\%$ & $\%$ \\
\hline 0.056 & 1.537 & 0.1966 & 0.1572 & 0.1594 & -18.91 & 1.42 \\
\hline 0.113 & 3.073 & 0.7126 & 0.5844 & 0.5760 & -19.17 & -1.43 \\
\hline 0.169 & 4.610 & 1.6039 & 1.3465 & 1.3413 & -16.37 & -0.39 \\
\hline 0.226 & 6.147 & 2.9919 & 2.5688 & 2.5628 & -14.34 & -0.23 \\
\hline 0.282 & 7.684 & 4.9033 & 4.2803 & 4.4054 & -10.15 & 2.92 \\
\hline 0.339 & 9.220 & 8.8286 & 7.9732 & 7.8735 & -10.82 & -1.25 \\
\hline 0.384 & 10.450 & 19.5344 & 18.4706 & 17.3691 & -11.08 & -5.96 \\
\hline
\end{tabular}
methods, and the total resistance values, which are obtained CFD analyses, for 148/3 coded boat

Table 18 The comparison between the total resistance values, which are obtained from Froude and Hughes

\begin{tabular}{|c|c|c|c|c|c|c|}
\hline \multicolumn{5}{|c|}{$148 / 4$} & \multicolumn{2}{|c|}{ Difference Percentages } \\
\hline \multirow[t]{2}{*}{ Fn } & \multirow{2}{*}{$\begin{array}{c}\mathrm{V}_{\mathrm{S}} \\
{[\mathrm{knot}]}\end{array}$} & $\begin{array}{l}\text { Froude } \\
\text { Method }\end{array}$ & $\begin{array}{l}\text { Hughes } \\
\text { Method }\end{array}$ & CFD & $\begin{array}{c}\text { According to } \\
\text { Froude Method }\end{array}$ & $\begin{array}{c}\text { According to } \\
\text { Hughes Method }\end{array}$ \\
\hline & & $\mathrm{R}_{\mathrm{T}}[\mathrm{kN}]$ & $\mathrm{R}_{\mathrm{T}}[\mathrm{kN}]$ & $\mathrm{R}_{\mathrm{T}}[\mathrm{kN}]$ & $\%$ & $\%$ \\
\hline 0.056 & 1.537 & 0.2166 & 0.1705 & 0.1636 & -24.47 & -4.06 \\
\hline 0.113 & 3.073 & 0.7720 & 0.6220 & 0.6049 & -21.64 & -2.75 \\
\hline 0.169 & 4.610 & 1.8182 & 1.5171 & 1.4557 & -19.94 & -4.05 \\
\hline 0.226 & 6.147 & 3.7615 & 3.2666 & 3.0006 & -20.23 & -8.14 \\
\hline 0.282 & 7.684 & 8.0444 & 7.3157 & 6.5601 & -18.45 & -10.33 \\
\hline 0.339 & 9.220 & 16.2584 & 15.2579 & 12.9917 & -20.09 & -14.85 \\
\hline 0.384 & 10.450 & 31.5449 & 30.3005 & 26.0765 & -17.34 & -13.94 \\
\hline
\end{tabular}
methods, and the total resistance values, which are obtained CFD analyses, for 148/4 coded boat 
Table 19 The comparison between the total resistance values, which are obtained from Froude and Hughes methods, and the total resistance values, which are obtained CFD analyses, for 148/8 coded boat

\begin{tabular}{|c|c|c|c|c|c|c|}
\hline \multicolumn{5}{|c|}{$148 / 8$} & \multicolumn{2}{|c|}{ Difference Percentages } \\
\hline \multirow[t]{2}{*}{ Fn } & \multirow{2}{*}{$\begin{array}{c}\mathrm{V}_{\mathrm{S}} \\
{[\mathrm{knot}]}\end{array}$} & $\begin{array}{l}\text { Froude } \\
\text { Method }\end{array}$ & $\begin{array}{l}\text { Hughes } \\
\text { Method }\end{array}$ & CFD & $\begin{array}{l}\text { According to } \\
\text { Froude Method }\end{array}$ & $\begin{array}{c}\text { According to } \\
\text { Hughes Method }\end{array}$ \\
\hline & & $\mathrm{R}_{\mathrm{T}}[\mathrm{kN}]$ & $\mathrm{R}_{\mathrm{T}}[\mathrm{kN}]$ & $\mathrm{R}_{\mathrm{T}}[\mathrm{kN}]$ & $\%$ & $\%$ \\
\hline 0.047 & 1.537 & 0.2186 & 0.1985 & 0.1934 & -11.52 & -2.56 \\
\hline 0.094 & 3.073 & 0.7627 & 0.6969 & 0.6943 & -8.97 & -0.37 \\
\hline 0.142 & 4.610 & 1.6997 & 1.5669 & 1.5538 & -8.58 & -0.84 \\
\hline 0.189 & 6.147 & 3.1587 & 2.9398 & 2.9331 & -7.14 & -0.23 \\
\hline 0.246 & 7.991 & 5.6142 & 5.2683 & 5.3006 & -5.59 & 0.61 \\
\hline 0.302 & 9.835 & 9.7795 & 9.2822 & 9.2407 & -5.51 & -0.45 \\
\hline 0.378 & 12.294 & 25.6370 & 24.9015 & 22.9937 & -10.31 & -7.66 \\
\hline
\end{tabular}

Table 20 The comparison between the total resistance values, which are obtained from Froude and Hughes methods, and the total resistance values, which are obtained CFD analyses, for 148/9 coded boat

\begin{tabular}{|c|c|c|c|c|c|c|}
\hline \multicolumn{5}{|c|}{$148 / 9$} & \multicolumn{2}{|c|}{ Difference Percentages } \\
\hline Fn & $\mathrm{V}_{\mathrm{S}}$ & $\begin{array}{l}\text { Froude } \\
\text { Method }\end{array}$ & $\begin{array}{l}\text { Hughes } \\
\text { Method } \\
\end{array}$ & CFD & $\begin{array}{c}\text { According to } \\
\text { Froude Method }\end{array}$ & $\begin{array}{c}\text { According to } \\
\text { Hughes Method }\end{array}$ \\
\hline & & $\mathrm{R}_{\mathrm{T}}[\mathrm{kN}]$ & $\mathrm{R}_{\mathrm{T}}[\mathrm{kN}]$ & $\mathrm{R}_{\mathrm{T}}[\mathrm{kN}]$ & $\%$ & $\%$ \\
\hline 0.047 & 1.537 & 0.2170 & 0.1932 & 0.1937 & -10.74 & 0.24 \\
\hline 0.094 & 3.073 & 0.7752 & 0.6972 & 0.7077 & -8.70 & 1.51 \\
\hline 0.142 & 4.610 & 1.7191 & 1.5621 & 1.6078 & -6.48 & 2.93 \\
\hline 0.189 & 6.147 & 3.3454 & 3.0866 & 3.1368 & -6.24 & 1.63 \\
\hline 0.246 & 7.991 & 7.7329 & 7.3240 & 7.2269 & -6.54 & -1.33 \\
\hline 0.302 & 9.835 & 15.4127 & 14.8248 & 13.0811 & -15.13 & -11.76 \\
\hline 0.368 & 11.987 & 35.0224 & 34.1909 & 29.9300 & -14.54 & -12.46 \\
\hline
\end{tabular}

When the velocity increases, it is observed that the percentage of difference between CFD results and test data rises while calculating the total resistance of the ship with CFD because of the difficulty in accurately modeling the turbulence phenomenon.

Turbulence density, turbulence velocity scale and turbulence viscosity ratio values are taken constant for each ship form and speed in the ship resistance calculation problems with CFD. In this study, the constants, which are suggested by the instruction manual of CFD program [33], are adopted for the values of turbulence intensity, turbulence velocity scale and turbulence viscosity ratio. Block coefficient of $148 / 3$ and 148/8 coded boats are averages 0.405 while block coefficient of $148 / 4$ and $148 / 9$ coded boats are averages 0.495 . The total resistance values of 148/4 and 148/9 coded boats, i.e., at the boats with high $\mathrm{C}_{\mathrm{B}}$ value, are calculated with a greater percentage of difference than the total resistance values of $148 / 3$ and 148/8 coded boats because the flow around the underwater forms of 148/4 and 148/9 coded boats is more turbulent.

CFD analyses of forms with delta, nabla and elliptical bulb are carried out with the program settings and constants, which are used in CFD analyses for 148/3, 148/4, 148/8 and $148 / 9$ coded boats. 


\subsection{Comparison of CFD results for the boats without bulb and with bulb}

The total resistance values are calculated by performing CFD analyses for 148/3, 148/3D, 148/3-N, 148/3-E, 148/4, 148/4-D, 148/4-N, 148/4-E, 148/8, 148/8-D, 148/8-N, 148/8-E, 148/9, 148/9-D, 148/9-N and 148/9-E coded fishing boats at the determined Fn values. The difference percentages of the total resistance values of forms with bulb according to forms without bulb are calculated according to equation_11.

$$
\text { Difference Percentage }=\frac{R_{T}(\text { with bulb })-R_{T}(\text { without bulb })}{R_{T}(\text { without bulb })} \times 100
$$

The comparison between total resistance of the forms with bulb and total resistance of the forms without bulb are done via Equation (11). Thus, it is determined that, how much increase (+) or decrease (-) are on the total resistance according to the bulb shapes.

The values of friction resistance and pressure resistance, which constitute the total resistance of the ship, are shown in Figure 10, 11, 12 and 13 for 148/3, 148/4, 148/8 and 148/9 coded boats, respectively.

As can be seen from Figure 10, Figure 11, Figure 12 and Figure 13 frictional resistance is higher than pressure resistance at low Fn values while pressure resistance is higher than frictional resistance at high Fn values. While the frictional resistance is higher at boat forms with bulb according to forms without bulb, the pressure resistance is less at forms with bulb than at forms without bulb. In general, the most significant decrease in pressure resistance is seen by elliptical type bulb and this is followed by nabla and delta type bulbs.

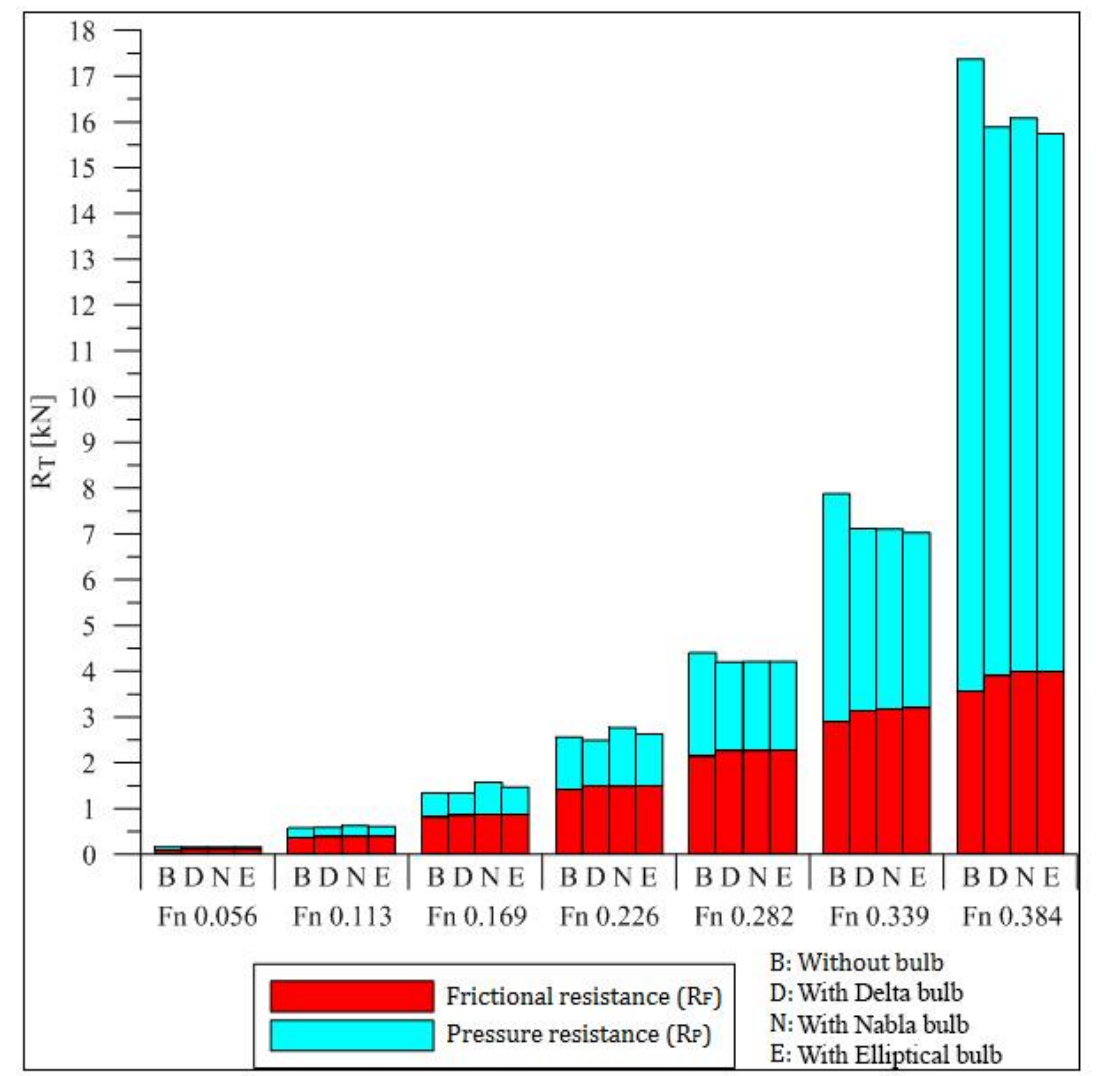

Fig. 10 The total resistance values, which are obtained using CFD, for 148/3, 148/3-D, 148/3-N and 148/3-E coded boats 


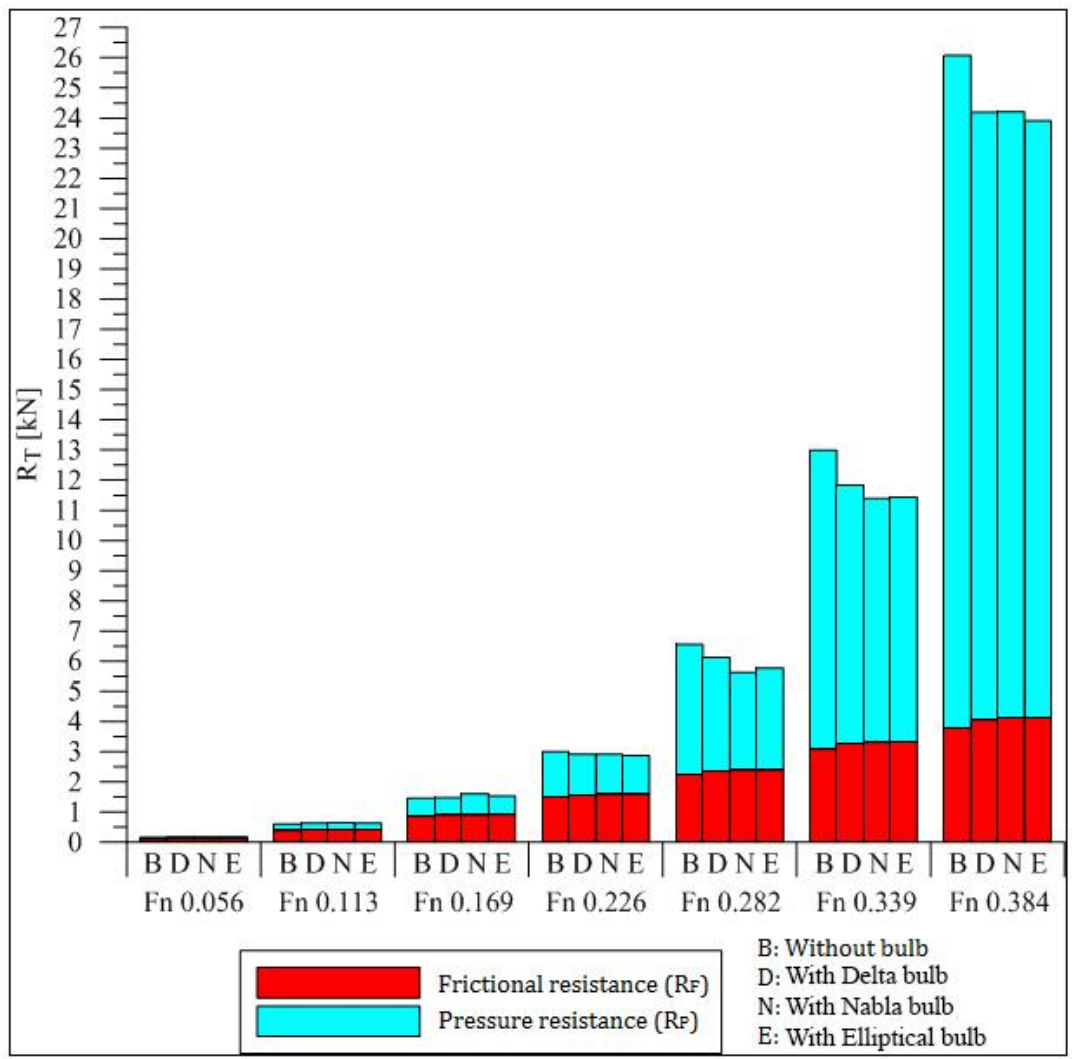

Fig. 11 The total resistance values, which are obtained using CFD, for 148/4, 148/4-D, 148/4-N and 148/4-E coded boats

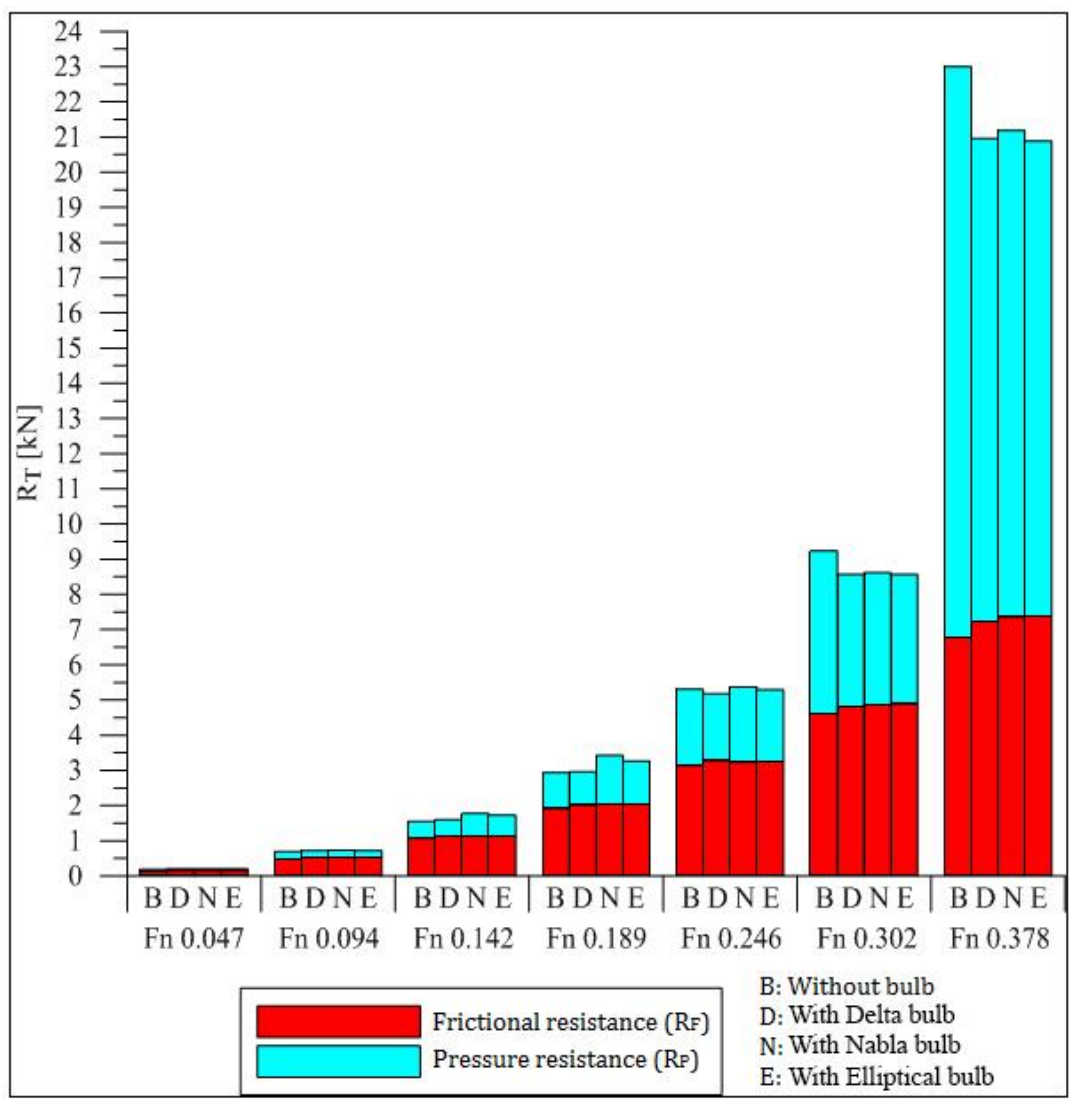

Fig. 12 The total resistance values, which are obtained using CFD, for 148/8, 148/8-D, 148/8-N and 148/8-E coded boats 


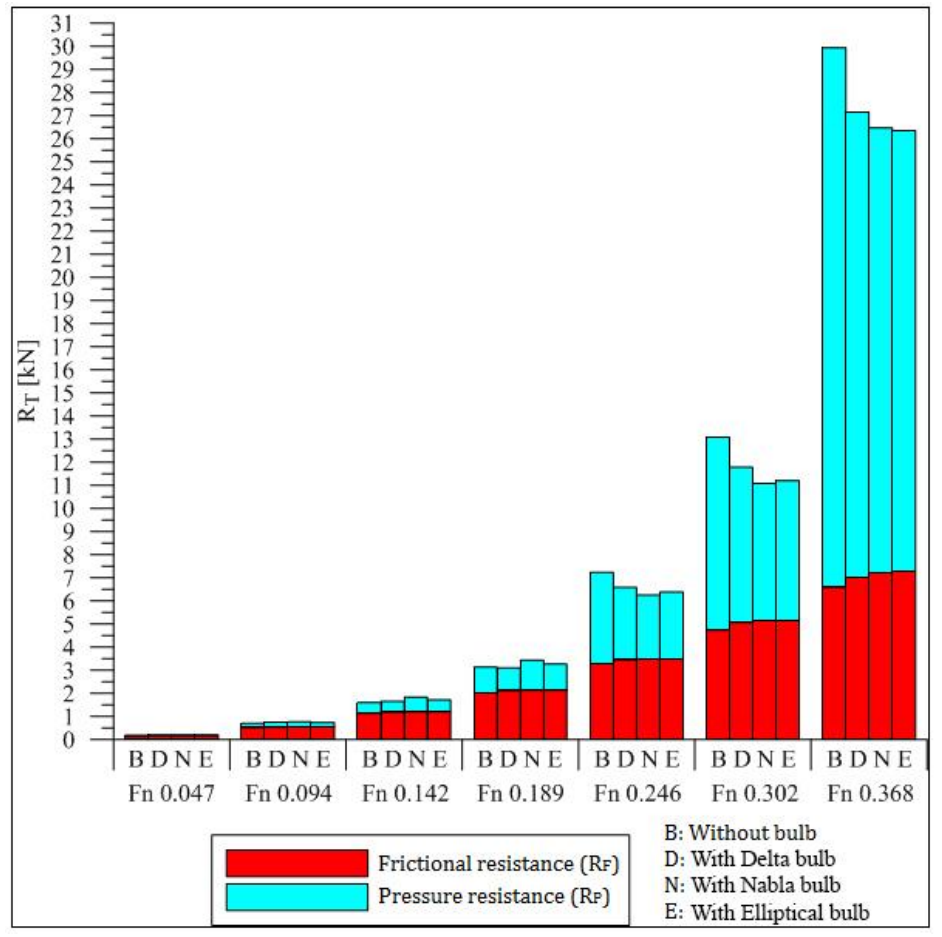

Fig. 13 The total resistance values, which are obtained using CFD, for 148/9, 148/9-D, 148/9-N and 148/9-E coded boats

At the specified Fn numbers, increase $(+)$ or decrease (-) percentages of the total resistance values of the 148/3-D, 148/3-N and 148/3-E coded boats with respect to 148/3 coded boat are shown in Figure 14.

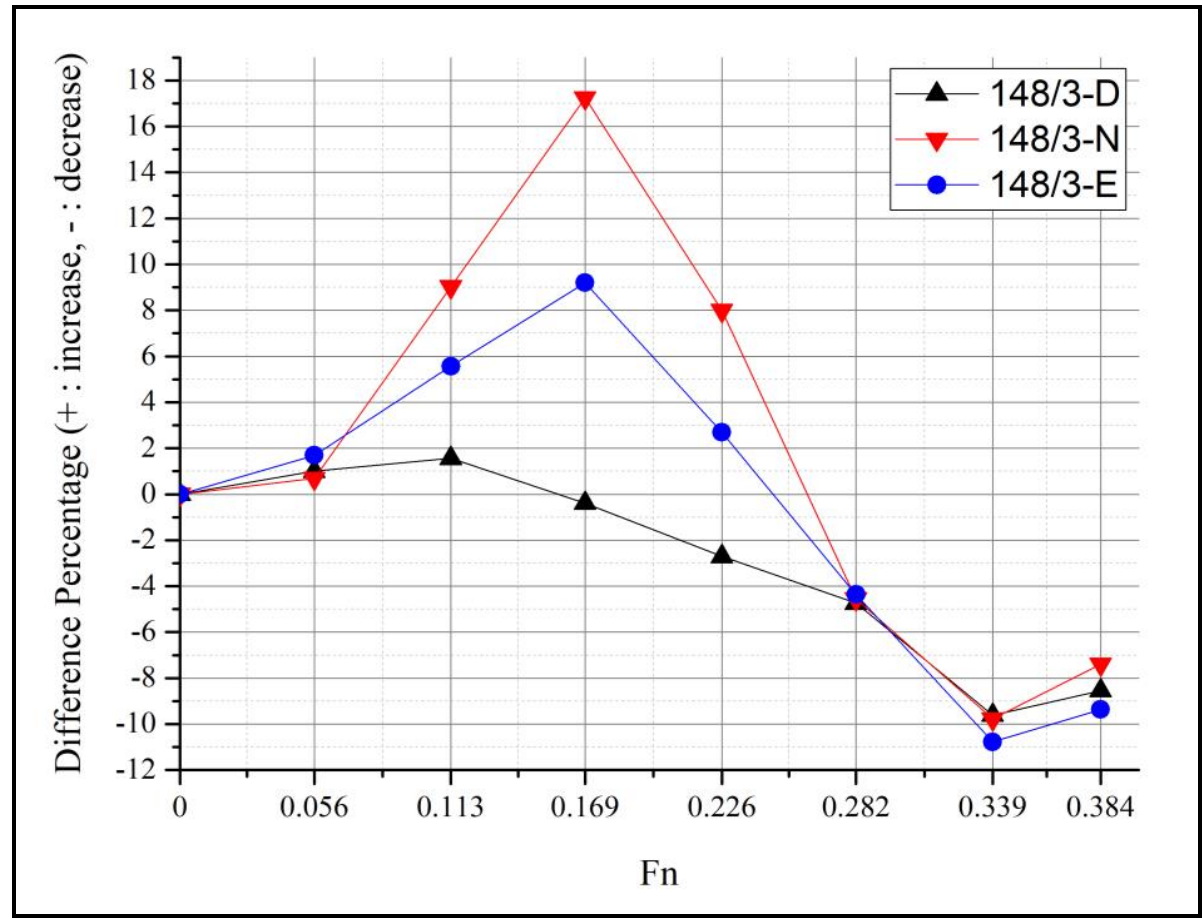

Fig. 14 According to Fn values, increase (+) or decrease (-) percentages of the total resistance values of $148 / 3-\mathrm{D}, 148 / 3-\mathrm{N}$ and $148 / 3-\mathrm{E}$ in reference to $148 / 3$. 
As can be seen in the Figure 14 for 148/3 coded fishing boat, delta, nabla and elliptical bulbs start to become effective after value of Fn 0.158, Fn 0.261 and Fn 0.246 value, respectively. In other words; the delta, nabla and elliptical bulb are beginning to provide benefit after 4.3, 7.1 and 6.7 knot speeds, respectively. The three bulb types also provide the maximum benefit at value of Fn 0.339, namely, at the speed of 9.2 knots. At value of Fn 0.384 , i.e., at a speed of 10.50 knots, the efficiency of the bulbs is somewhat lower than that of Fn 0.339. At 10 knot service speed and higher speeds, the elliptical type bulb provides the most benefit. While delta and nabla bulb have same benefit at the service speed, the delta bulb more useful than the nabla bulb at low speeds. It is the type of elliptical bulb that provides the most benefit at service speed.

At the specified Fn numbers, increase (+) or decrease (-) percentages of the total resistance values of the 148/4-D, 148/4-N and 148/4-E coded boats with respect to 148/4 coded boat are shown in Figure 15.

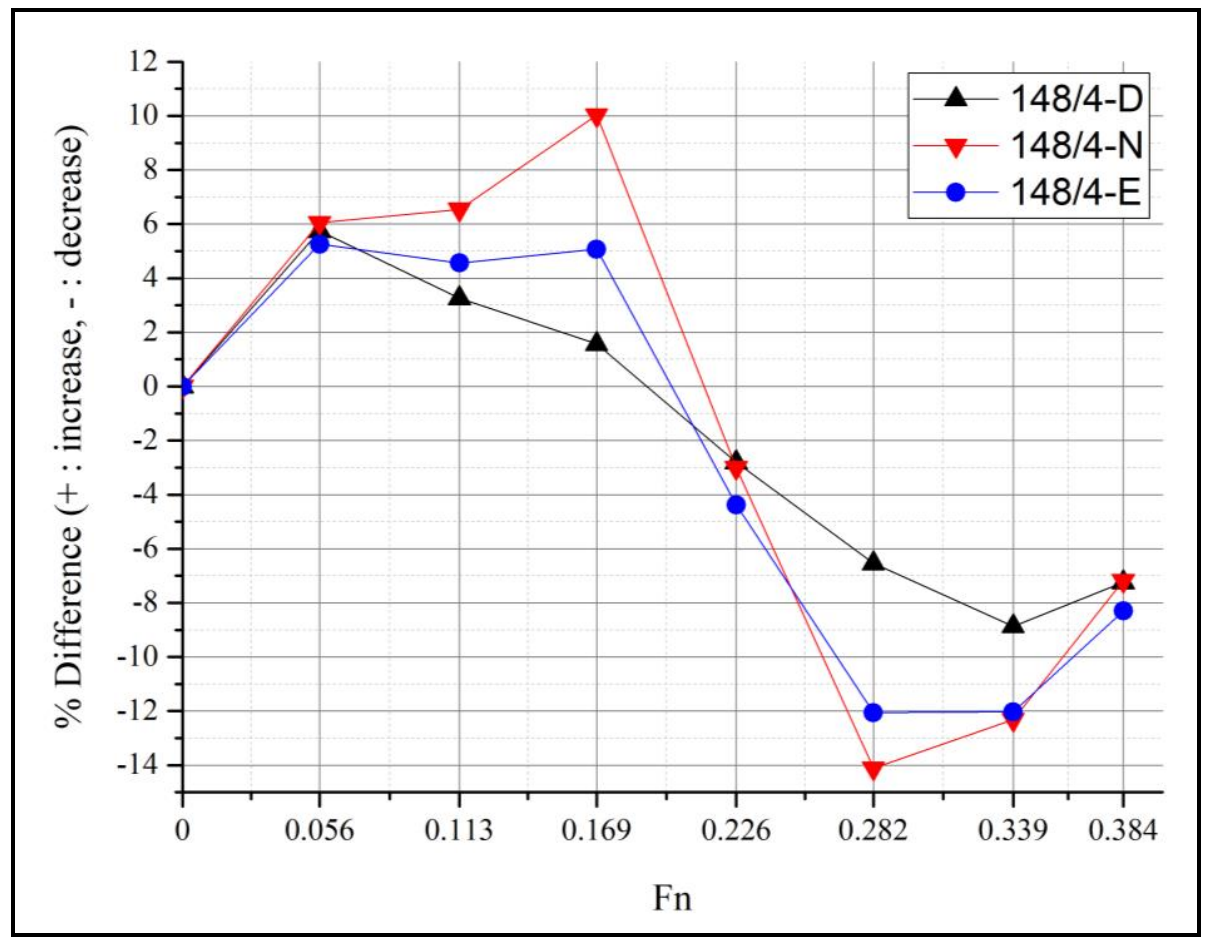

Fig. 15 According to Fn values, increase (+) or decrease (-) percentages of the total resistance values of $148 / 4-\mathrm{D}, 148 / 4-\mathrm{N}$ and 148/4-E in reference to $148 / 4$.

As can be seen in the Figure 15 for 148/4 coded fishing boat, delta, nabla and elliptical bulbs start to become effective after value of Fn 0.189, Fn 0.213 and Fn 0.200, respectively. In other words; the delta, nabla and elliptical bulb are beginning to provide benefit after 5.1, 5.8 and 5.4 knot speeds, respectively. The nabla and elliptical type bulb provide the maximum benefit at value of Fn 0.282, namely, at the speed of 7.6 knots. The delta bulb type also provides the maximum benefit at value of Fn 0.339, namely, at the speed of 9.2 knots. It is also seen that the nabla bulb form is more useful than the elliptical type bulb at the speed range of 6.7-9.2 knots. At the service speed of 10 knots and and higer speeds, the elliptical type of bulb is the most beneficial, while the nabla type bulb is more beneficial than the elliptical type bulb at speed of between 6.7 and 9.2 knots.

At the specified Fn numbers, increase $(+)$ or decrease $(-)$ percentages of the total resistance values of the 148/8-D, 148/8-N and 148/8-E coded boats with respect to 148/8 coded boat are shown in Figure 16. 


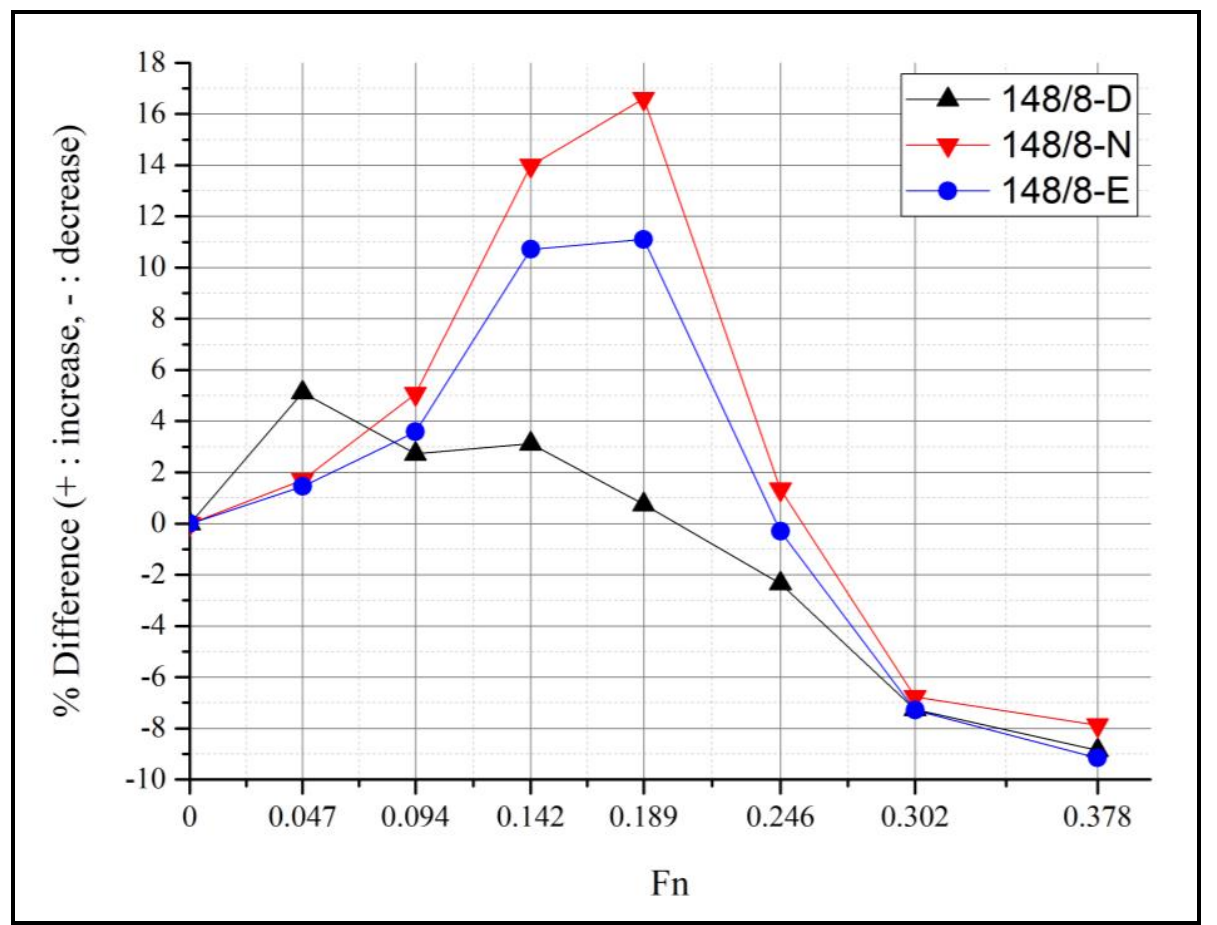

Fig. 16 According to Fn values, increase (+) or decrease (-) percentages of the total resistance values of $148 / 8-\mathrm{D}, 148 / 8-\mathrm{N}$ and $148 / 8$-E in reference to $148 / 8$.

As can be seen in the Figure 16 for 148/8 coded fishing boat, delta, nabla and elliptical bulbs start to become effective after value of Fn 0.204, Fn 0.257 and Fn 0.246, respectively. In other words; the delta, nabla and elliptical bulb are beginning to provide benefit after 6.6, 8.4 and 8.0 knot speeds, respectively. The three bulb types also provide the maximum benefit at value of Fn 0.378 , namely, at the speed of 12.3 knots. In addition, the delta bulb form performs better than the elliptical type bulb at low Fn numbers. While at the 10 knot service speed and higer speeds the elliptical type bulb provides more benefits, the delta type bulb provides more benefits at lower speeds. The three types of bulbs are the same benefit at service speed, but at lower speeds it appears that the delta type bulb is more useful than the other types of bulbs.

At the specified Fn numbers, increase (+) or decrease (-) percentages of the total resistance values of the 148/9-D, 148/9-N and 148/9-E coded boats with respect to 148/9 coded boat are shown in Figure 17.

As can be seen in the Figure 17 for 148/9 coded fishing boat, delta, nabla and elliptical bulbs start to become effective after value of Fn 0.177, Fn 0.213 and Fn 0.205, respectively. In other words; the delta, nabla and elliptical bulb are beginning to provide benefit after 5.8, 6.9 and 6.7 knot speeds, respectively. The three bulb types also provide the maximum benefit at value of Fn 0.302, namely, at the speed of 9.8 knots. It is also seen that the nabla bulb form is more useful than the elliptical type bulb at the speed range of 7.6-11.5 knots. While the elliptical type bulb is more useful than the nabla type bulb at the speed range of 0.0-7.6 knots, the nabla type bulb is more useful than the elliptical type bulb at the speed range of 7.6-11.5 knots. After the speed of 11.5 knots, the elliptical type bulb is more useful. 


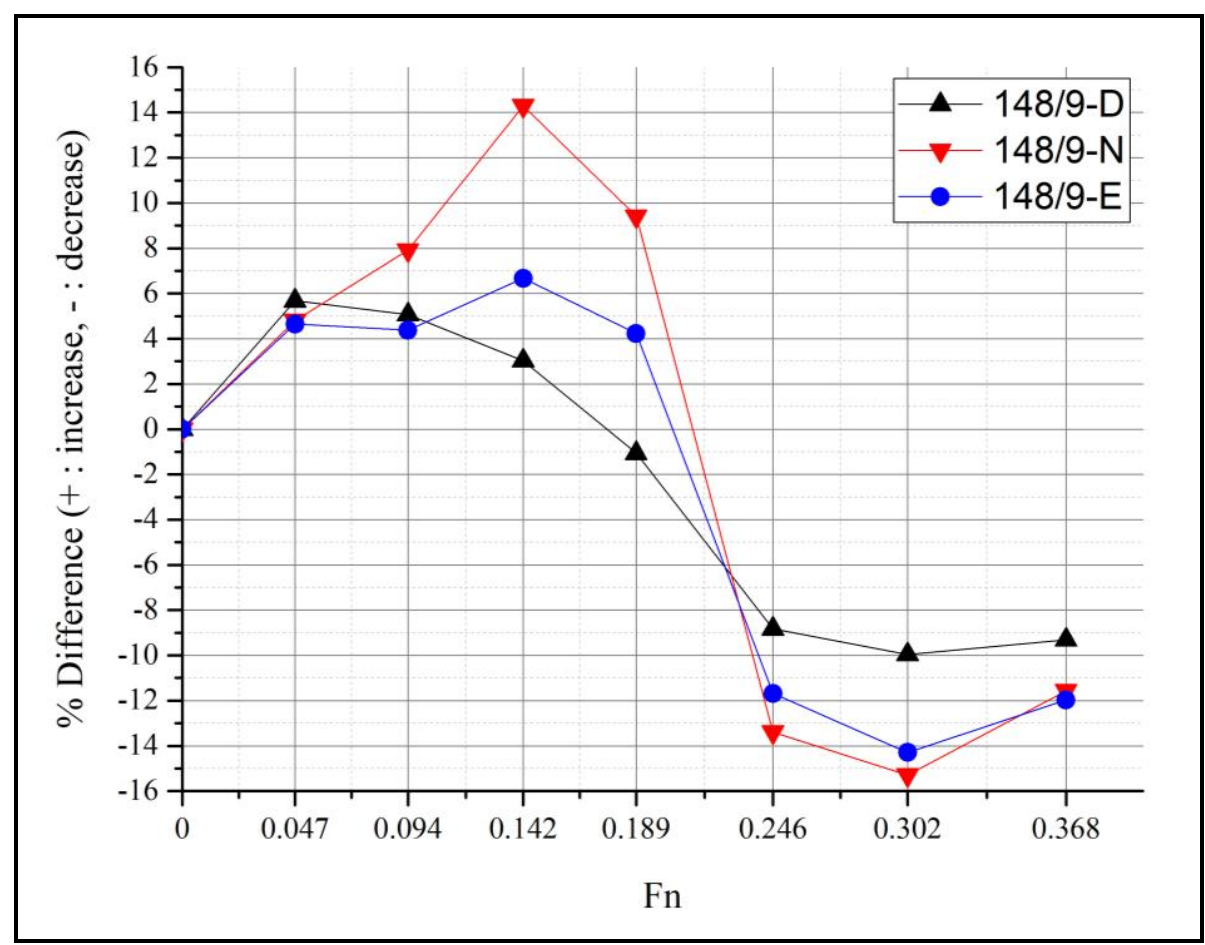

Fig. 17 According to Fn values, increase (+) or decrease (-) percentages of the total resistance values of $148 / 9-\mathrm{D}, 148 / 9-\mathrm{N}$ and 148/9-E in reference to $148 / 9$.

When all of the percentages of increase and decrease in total resistance are evaluated together, it turns out that the most suitable bulb form for 148/3, 148/4, 148/8 and 148/9 coded fishing boats is the elliptical bulb type at service speed of 10 knots and at higher speeds.

According to $C_{B}$, when the efficiency of the bulb is evaluated at the service speed of 10 knots;

- At the $\mathrm{C}_{\mathrm{B}} 0.405$, value of the benefit of the bulbs is $10 \%$ on average.

- At the $\mathrm{C}_{\mathrm{B}} 0.495$, value of the benefit of the bulbs is $13 \%$ on average.

The higher the $C_{B}$ value, the greater the benefit that the bulbs have at the service speed. Also, as the $C_{B}$ value increases, the speed range at which the bulbs maximum benefit is also increasing.

When the effectiveness of bulbs is evaluated according to L / B ratio;

- It has been found that the bulbs have started to benefit at lower speeds in boats with the $\mathrm{L} / \mathrm{B}$ ratio of 3.5 compared to boats with the $\mathrm{L} / \mathrm{B}$ ratio of 5.0.

- At 10 knots service speed, it has been determined that the bulbs benefit at average rate of $11 \%$ at boats with the $\mathrm{L} / \mathrm{B}$ ratio of 3.5 , and at average of $10 \%$ at boats with the $\mathrm{L} / \mathrm{B}$ ratio of 5.0.

It has been found that the bulbs have started to benefit at lower speeds in boats with the $\mathrm{L} / \mathrm{B}$ ratio of 3.5 compared to boats with the $\mathrm{L} / \mathrm{B}$ ratio of 5.0. At the $\mathrm{L} / \mathrm{B}$ ratio of 3.5 , bulbs have been found to be more beneficial in service speed.

When the efficiencies are evaluated according to types of bulbs;

- It has been found that the delta type bulb is beginning to provide benefit after the speed of 5.4 knots. It has an average benefit of $8.9 \%$ at the service speed.

- It has been found that the nabla type bulb is beginning to provide benefit after the speed of 7.0 knots. It has an average benefit of $11.0 \%$ in service speed. 
- It has been found that the elliptical type bulb is beginning to provide benefit after the speed of 6.7 knots. It has an average benefit of $11.2 \%$ in service speed.

At different low speeds, the delta, nabla and elliptical type bulbs cause $4 \%, 14 \%$ and $8 \%$ increase in total resistance, recpectively.

As an example, the wave deformations in the boat symmetry plane and the wave deformations on the free water surface at Fn 0.339 of the 148/3, 148/3-D, 148/3-N and 148/3E coded fishing boats are shown in Figure 18 and 19, respectively.
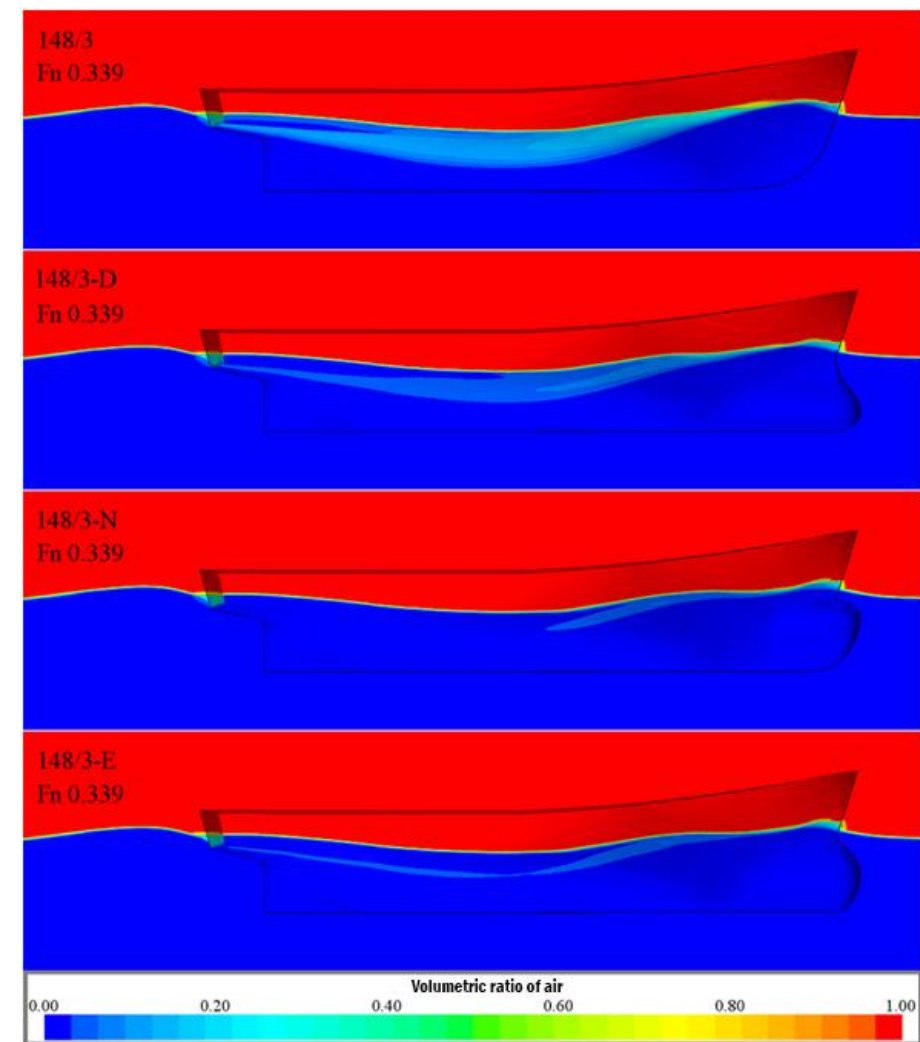

Fig. 18 Wave deformations occurring in the boat symmetry plane of 148/3, 148/3-D, 148/3-N and 148/3-E coded boats at Fn 0.339

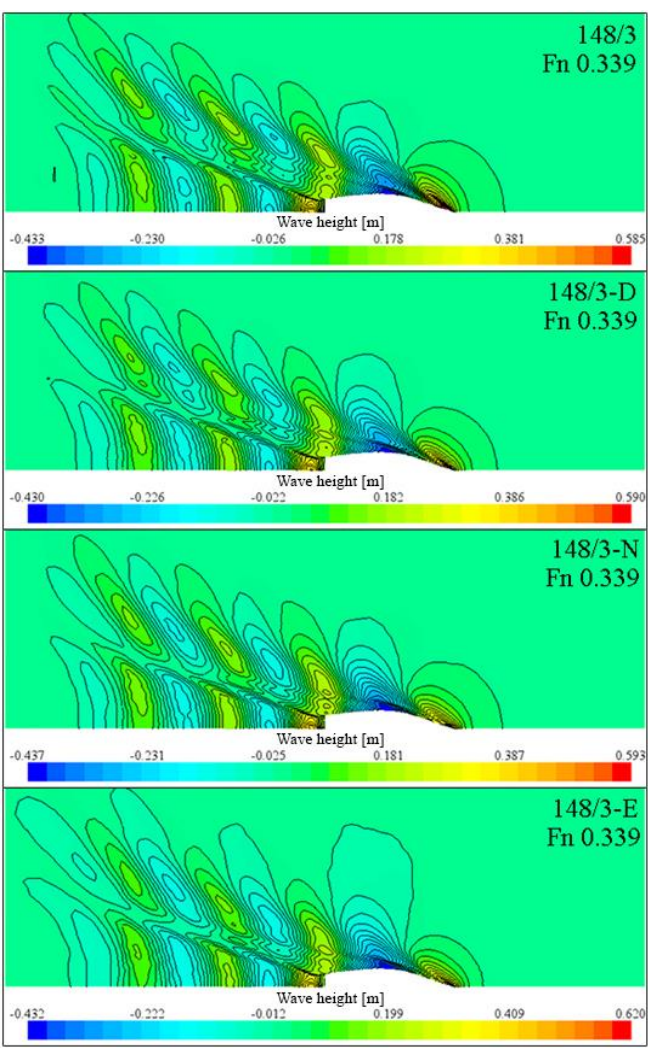

Fig. 19 Wave deformations at the free water surface of 148/3, 148/3-D, 148/3-N and 148/3-E coded boats at Fn 0.339

\section{Conclusions}

The delta, nabla and elliptic type bulbs are applied to 148/3, 148/4, 148/8 and 148/9 coded boats from ITU Fishing Boats Series in order to find out which type of bulb is more effective on the fishing boats. In order to inspect the accuracy of the CFD analyses, the total resistance values, which are obtained by the Froude and Hughes methods from the test results of the 148/3,148/4,148/8 and 148/9 coded boats, are compared with the total resistance values which are obtained by CFD. The CFD analyses of 148/3, 148/4, 148/8 and 148/9 coded boats forms with delta, nabla and elliptic type bulb are performed. The total resistance values of the forms with bulbs and without bulbs are compared. The results are evaluated according to boat forms, $\mathrm{C}_{\mathrm{B}}, \mathrm{L} / \mathrm{B}$ ratio and the efficiencies of the bulbs.

When the results are evaluated according to boat forms, it is seen that elliptic type bulb is found to be more useful than other type bulbs at range of 0-12 knots. 
When the results are evaluated according to $C_{B}$, it has been found that the boats with high $\mathrm{C}_{\mathrm{B}}$ have more benefit of bulb. Also, as the $\mathrm{C}_{\mathrm{B}}$ increases, the ratio of the bulb efficiency increases.

When the results are evaluated according to the L/B ratio, it has been found that the bulbs have started to benefit at lower Fn values in boats with the low L/B ratio compared to boats with the high $\mathrm{L} / \mathrm{B}$ ratio. Also, the efficiency rate is found to be higher.

When the results were evaluated according to the type of bulbs, it is seen that the delta type bulb starts to be benefit in lower Fn values and it is followed by elliptical and nabla type. On the contrary, around at the service speed and at higher speeds, the elliptical type bulb is more useful than other bulbs and it is followed by the nabla and the delta type.

When all the evaluations are considered, it seems that the most suitable bulb is the elliptical type bulb for fishing boats.

\section{REFERENCES}

[1] Kafali, K., 1982. Static and Dynamic Principles of Ship Forms, ITU Library, Istanbul, Turkey.

[2] Kracht, A. M., 1978. Design of Bulbous Bows, Transactions SNAME, 86,197-217.

[3] Taylor, D. W., 1923. Marine Engineering and Shipping Age, 540-548.

[4] Bragg, M., 1930. Results of Experiments upon Bulbous Bows, Transactions SNAME, 38,13-43.

[5] Inui, T., Takaehi, T. and Kumano, M., 1960. Wave Profile Measurement on the Wave Making Characteristics of the Bulbous Bow, Society of Naval Architects of Japan (Translation from the University of Michigan), 16-35.

[6] Ferguson, A. M., 1967. Hull and Bulbous Bow Interaction, Transactions RINA, 421-441.

[7] Muntjewerf, J. J., 1967. Methodical Series Experiments on Cylindrical Bows, Transactions RINA, 199 223.

[8] Weinblum, G., 1935. Die Theorie der Wulstschiffe, Der Gesellshaft fur Angevandte Mathematik, 135156.

[9] Wigley, W. C. S., 1936. The Theory of Bulbous Bow and its Practical Application, Transactions NECIES, 52,65-88.

[10] Inui, T., 1962. Wave Making Resistance of Ships, Transactions SNAME, 70,283-313.

[11] Yim, B., 1963. On Ships with Zero and Small Wave Resistance, Paper presented at the in Proceedings of International Seminar on Theoretical Wave Resistance, Michigan, USA, 163-193. https://doi.org/10.21236/AD0414680.

[12] Yim, B., 1965. Analyses of Spherical Bulbs on a Ship Bow, Inc. Technical Report 117, 28-39.

[13] Yim, B., 1974. A Simple Design Theory and Method for Bulbous Bows of Ships, Journal of Ship Research, 18,3, 141-152.

[14] Yim, B., 1980. Simple Calculation of Sheltering Effect on Ship-Wave Resistance and Bulbous Bow Design, Journal of Ship Research, 24,4, 232-243.

[15] Baba, E., 1969. A New Component of Viscous Resistance of Ships, Transactions of the Society of Naval Architects of Japan, 125,69-81. https://doi.org/10.2534/jjasnaoe1968.1969.23.

[16] Shearer, J. R. and Steele, B. N., 1970. Some Aspects of the Resistance of Full Form Ships, Transactions RINA, 69-83.

[17] Sharma, R. and Sha, O. P., 2005. Practical Hydrodynamic Design of Bulbous Bows for Ships, Naval Engineers Journal, 117,1, 57-75. https://doi.org/10.1111/j.1559-3584.2005.tb00321.x.

[18] Godunov, S. K., 1959. A Difference Method for Numerical Calculation of Discontinuous Solutions of The Equations of Hydrodynamics, Matematicheskii Sbornik, 89,3, 271-306.

[19] Shih, T. H., Liou, W. W., Shabbir, A., Yang, Z. and Zhu, J., 1995. A New k - $E$ Eddy-Viscosity Model for High Reynolds Number Turbulent Flows-Model Development and Validation, Computers Fluids, 24,3, 227-238. https://doi.org/10.1016/0045-7930(94)00032-T.

[20] Stromgren, C., 1995. A Comparison of Alternative Bow Configurations, Marine Technology, 32,3, 224230 . 
[21] Kim, K. J. and Jang, Y. H., 1996. Investigation of the Effects of Bulbous Bows on the Ship Wave Characteristics by CFD, Paper presented at the Proceedings KOJAM-96, Taejon, 197-213.

[22] Huang, C. H., Chiang, C. C. and Chou, S. K., 1998. An Inverse Geometry Design Problem in Optimizing Hull Surfaces, Journal of Ship Research, 42,2, 79-85.

[23] Lee, K. J. and Sarath, E. S., 2005. Optimized Design of Hull Form and Bulbous Bow for ULCS Proceedings of the Fifteenth, 715-721, Cupertino: International Society Offshore\&Polar Engineers.

[24] Sarasquete, A., Collazo, A. C., Coache, S., Meis, M. and Ruiz, V., 2012. Increased Energy Efficiency of The Fishing Fleet Due to Improved Hydrodynamic Performance, Paper presented at the Second International Symposium on Fishing Vessel Energy Efficiency, Vigo, Spain.

[25] Matulja, D., Dejhalla, R., 2013. Optimization of the Ship Hull Hydrodynamic Characteristics in Calm Water, Brodogradnja, 64, 4, 425-436

[26] Chrismianto, D. and Kim, D. J., 2014. Parametric Bulbous Bow Design Using The Cubic Bezier Curve and Curve-Plane Intersection Method for The Minimization of Ship Resistance in CFD, Journal of Marine Science and Technology, 19,4, 479-492. https://doi.org/10.1007/s00773-014-0278-x.

[27] Froude, W., 1872. "Experiments on the surface-friction experienced by a plane moving through water", 42nd Report of the British Association for the Advancement of Science, Brighton.

[28] Hughes, G., 1954. "Friction and Form Resistance in Turbulent Flow, and a Proposed Formulation for Use in Model and Ship Correlation, TINA, 96, 314.

[29] Kafalı, K., Şaylan, O. and Salc1, A., 1979. Developing of Hull Forms of Fishing Boats Suitable for Turkish Waters, The Scientific\&Technological Research Council of Turkey, Istanbul, Turkey. Project No. G-416.

[30] Aydin, M., 2002. Computer Aided Design of Fishing Boats Suitable for Turkish Waters, Ph.D. Thesis, Institute of Science and Technology of Istanbul Technical University, Istanbul, Turkey.

[31] Soylemez, M., 1983. Application of Bulb to Fishing Boats, Undergraduate Graduation Project, Istanbul Technical University, Faculty of Naval Architecture and Ocean Engineering, Istanbul, Turkey.

[32] Aydin, M. and Salci, A., 2008. Resistance Characteristics of Fishing Boats Series of ITU, Marine Technology, 45,4, 194-210.

[33] CD-Adapco, 2014. User Guide, Star-CCM+ Version 9.04, CD-adapco.

[34] ITTC, Fresh Water and Seawater Properties. http://ittc.info/downloads/Archive\%20of\%20recommended\%20procedures/2011\%20Recommended\%20P rocedures/7.5-02-01-03.pdf. 25 February 2016.

[35] Hirt, C. W. and Nichols, B. D., 1981. Volume of Fluid (VOF) Method for The Dynamics of Free Boundaries, Journal of Computational Physics, 39,1, 201-225. https://doi.org/10.1016/00219991(81)90145-5.

[36] Courant, R.; Friedrichs, K.; and Lewy, H., 1967. "On the Partial Difference Equations of Mathematical Physics." IBM J. 11, 215-234. https://doi.org/10.1147/rd.112.0215.

Submitted: 05.10.2017. Dursun Saral ${ }^{1}$, dursunsaral @ktu.edu.tr

Muhsin Aydin², muhsina@yildiz.edu.tr

Accepted: $\quad$ 15.01.2018. $\quad$ Ercan Kose ${ }^{1}$, ekose @ktu.edu.tr

${ }^{1}$ Department of Naval Architecture and Marine Engineering

Karadeniz Technical University, 61530 Trabzon Turkey

${ }^{2}$ Faculty of Naval Architecture and Maritime Yildiz Technical University, Istanbul, Turkey 